\title{
Experimental and Computational Studies of the Isomerization Reactions of Bidentate Phosphine Ligands in Triosmium Clusters: Kinetics of the Rearrangements from Bridged to Chelated Isomers and X-ray Structures

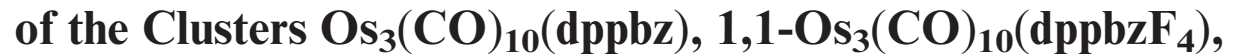 $\left.\mathrm{HOs}_{3}(\mathrm{CO})_{9}\left[\mu-1,2-\mathrm{PhP}_{\left(\mathrm{C}_{6}\right.} \mathrm{H}_{4}-\eta^{1}\right) \mathrm{C}_{6} \mathrm{H}_{4} \mathrm{PPh}_{2}\right]$, and $\mathrm{HOs}_{3}(\mathrm{CO})_{9^{-}}$ $\left[\mu-1,2-P h P\left(C_{6} H_{4}-\eta^{1}\right) C_{6} F_{4} P P_{2}\right]$
}

\author{
Xue Zhang, ${ }^{\dagger}$ ' Srikanth Kandala, ${ }^{\dagger}$ Li Yang, ${ }^{\dagger}$ William H. Watson,${ }^{\S}$ Xiaoping Wang,, \\ David A. Hrovat, ${ }^{\dagger}$, Weston Thatcher Borden, ${ }^{*}, \dagger$ and Michael G. Richmond*, \\ ${ }^{\dagger}$ Department of Chemistry and ${ }^{*}$ Center for Advanced Scientific Computing and Modeling, University of \\ North Texas, Denton, Texas 76203-5017, United States, ${ }^{\S}$ Department of Chemistry, Texas Christian \\ University, Fort Worth, Texas 76129, United States, and" Neutron Scattering Science Division, Oak Ridge \\ National Laboratory, Oak Ridge, Tennessee 37831, United States
}

Received August 11, 2010

\begin{abstract}
The diphosphine ligand 1,2-bis(diphenylphosphino)benzene (dppbz) reacts with the activated cluster $1,2-\mathrm{Os}_{3}(\mathrm{CO})_{10}(\mathrm{MeCN})_{2}(\mathbf{1})$ at room temperature to furnish a mixture of the triosmium clusters $1,2-\mathrm{Os}_{3}(\mathrm{CO})_{10}(\mathrm{dppbz})(\mathbf{2})$ and $1,1-\mathrm{Os}_{3}(\mathrm{CO})_{10}(\mathrm{dppbz})(\mathbf{3})$, along with a trace amount of the hydride cluster $\mathrm{HOs}_{3}(\mathrm{CO})_{9}\left[\mu-1,2-\mathrm{PhP}\left(\mathrm{C}_{6} \mathrm{H}_{4}-\eta^{1}\right) \mathrm{C}_{6} \mathrm{H}_{4} \mathrm{PPh}_{2}\right]$ (4). The dppbz-bridged cluster 2 forms as the kinetically controlled product and irreversibly transforms to the corresponding chelated isomer 3 at ambient temperature. The disposition of the dppbz ligand in $\mathbf{2}$ and $\mathbf{3}$ has been established by X-ray crystallography and ${ }^{31} \mathrm{P}$ NMR spectroscopy, and the kinetics for the conversion $\mathbf{2} \rightarrow \mathbf{3}$ have been followed by UV-vis spectroscopy in toluene over the temperature range $318-343 \mathrm{~K}$. The calculated activation parameters $\left(\Delta H^{\ddagger}=21.6(3) \mathrm{kcal} / \mathrm{mol} ; \Delta S^{\ddagger}=-11(1)\right.$ eu $)$ and lack of CO inhibition support an intramolecular isomerization mechanism that involves the simultaneous migration of phosphine and $\mathrm{CO}$ groups about the cluster polyhedron. The reaction between $\mathbf{1}$ and the fluorinated diphosphine ligand 1,2-bis(diphenylphosphino)tetrafluorobenzene $\left(\mathrm{dppbz}_{4}\right)$ was examined under similar reaction conditions and was found to afford the chelated cluster $1,1-\mathrm{Os}_{3}(\mathrm{CO})_{10}\left(\mathrm{dppbzF}_{4}\right)(\mathbf{6})$ as the sole observable product. The absence of the expected bridged isomer $1,2-\mathrm{Os}_{3}(\mathrm{CO})_{10}\left(\mathrm{dppbzF}_{4}\right)(\mathbf{5})$ suggests that the $\mathrm{dppbzF}_{4}$ ligand destabilizes $\mathbf{5}$, thus accounting for the rapid isomerization of $\mathbf{5}$ to $\mathbf{6}$. Near-UV irradiation of clusters $\mathbf{3}$ and $\mathbf{6}$ leads to $\mathrm{CO}$ loss and ortho metalation of an ancillary aryl group. The resulting hydride clusters 4 and $\mathrm{HOs}_{3}(\mathrm{CO})_{9}\left[\mu-1,2-\mathrm{PhP}\left(\mathrm{C}_{6} \mathrm{H}_{4}-\eta^{1}\right) \mathrm{C}_{6} \mathrm{~F}_{4} \mathrm{PPh}_{2}\right](7)$ have been isolated and fully characterized by spectroscopic and X-ray diffraction analyses. Both $\mathbf{4}$ and $\mathbf{7}$ react with added $\mathrm{CO}$ under mild conditions to regenerate $\mathbf{3}$ and $\mathbf{6}$, respectively, in quantitative yield. The rearrangements of bridged to chelated diphosphine complexes in this genre of decacarbonyl clusters have been investigated by DFT calculations. The computational results support a concerted process, involving the scrambling of equatorial $\mathrm{CO}$ and phosphine groups via a classical merry-go-round exchange scheme. The barriers computed for this mechanism agree well with those that have been measured, and steric compression within the bridged diphosphine groups of the reactants has been calculated to reduce the barrier heights for the rearrangement.
\end{abstract}

\section{Introduction}

Ligand fluxionality in polynuclear metal compounds is a well-established phenomenon. Numerous reports that unequivocally demonstrate the nonrigidity of $\mathrm{CO}, \mathrm{NO}, \mathrm{RNC}$, and hydride ligands may be found in the chemical literature dating back to the 1960s. ${ }^{1}$ In the absence of a ligand

*To whom correspondence should be addressed. W.T.B.: tel, 940-5653658; e-mail, borden@unt.edu. M.G.R.: tel, 940-565-3548; e-mail, cobalt@unt.edu. dissociation/association process (i.e. ligand on, ligand off), ${ }^{2}$ the permutation of a terminally bound $\left(\eta^{1}\right)$ ligand(s) between

(1) (a) Cotton, F. A.; Kruczynski, L.; Shapiro, B. L.; Johnson, L. F. J. Am. Chem. Soc. 1972, 94, 6191. (b) Adams, R. D.; Cotton, F. A. In Dynamic Nuclear Magnetic Resonance Spectroscopy; Jackman, L. M., Cotton, F. A., Eds.; Academic Press: New York, 1975; Chapter 12. (c) Farrugia, L. J. Dalton Trans. 1997, 1783. (d) Green, M.; Mead, K. A.; Mills, R. M.; Salter, I. D.; Stone, F. G. A.; Woodward, P. Chem. Commun. 1982, 51. (e) Musaev, D. G.; Nowroozi-Isfahani, T.; Morokuma, K.; Abedin, J.; Rosenberg, E.; Hardcastle, K. I. Organometallics 2006, 25, 203. 
different metal centers is assumed to proceed via an intermediate or transition structure, involving the simultaneous coordination of the ligand to two or more metal centers. The exact degree of ligand bridging depends upon the nuclearity of the metallic ensemble and the energetics of ligand exchange. ${ }^{3}$ The bulk of the published studies of intramolecular scrambling of an ancillary ligand(s) about a metal cluster indicate at least one terminal-bridge-terminal transposition of the migratory ligand(s). These ligands exhibit a high degree of coordinative flexibility, and they display a gamut of bonding modes from terminal $\left(\eta^{1}\right)$ to multisite, face-capping $\left(\mu_{4}\right)$ coordination. ${ }^{3,4}$

Tertiary phosphine and phosphite ligands are regarded as good $\sigma$ donors and they can also function as $\pi$-acceptor ligands, depending upon the nature of the ancillary substituents. ${ }^{5}$ Historically, such pnictogen ligands have been assumed to serve as terminal or $\eta^{1}$ ligands, and their coordination chemistry has been assumed to be restricted to a single metal site, irrespective of the nuclearity of the compound. ${ }^{6}$ This provincial view, in which a phosphine acts as a $2 \mathrm{e}$ donor through electron-precise bonding to only a single metal center, has recently been challenged, and crystallographic and solution NMR data have provided irrefutable confirmation for the ligation of two or more metal centers by $\mathrm{PF}_{3}$ and $\mathrm{PR}_{3}$ ligands.

The first structural demonstration of nontraditional bonding between a tertiary phosphine and a polynuclear cluster may be traced to the study by Balch of the reaction of $\mathrm{Pd}_{2}(\mu$ dppm $)_{2} \mathrm{Cl}_{2}$ with $\mathrm{PF}_{3}$, which affords the trinuclear cluster $\left[\mathrm{Pd}_{3}\left(\mu_{3}-\mathrm{PF}_{3}\right)(\mu-\mathrm{Cl})(\mu \text {-dppm })_{3}\right]^{+}$. $^{7}$ The capping of one of the triangular faces in the $\mathrm{Pd}_{3}$ cluster by the ancillary $\mathrm{PF}_{3}$ ligand defies description within a valence-bond perspective. An electron-deficient or delocalized model of bonding is required in order to describe the interaction involving the metallic core and the ancillary $\mathrm{PF}_{3}$ ligand. ${ }^{8}$ Other notable structures, containing dimetallic motifs that are bridged by a tertiary phosphine group(s), have been reported by the Werner and Réau groups., 90

The bridging-to-chelating isomerization of the diphosphine ligand in $\mathrm{H}_{4} \mathrm{Ru}_{4}(\mathrm{CO})_{10}$ (dppe), discovered by Shapley and Churchill, represents the first demonstrable example of a

(2) For ligand substitution reactions involving dissociative and associative manifolds, see: (a) Vanni, H.; Merbach, A. E. Inorg. Chem. 1979, 18, 2758. (b) Kowaleski, R. M.; Basolo, F.; Trogler, W. C.; Ernst, R. D. J. Am. Chem. Soc. 1986, 108, 6046. (c) Turaki, N. N.; Huggins, J. M.; Lebioda, L. Inorg. Chem. 1988, 27, 424.

(3) Band, E.; Muetterties, E. L. Chem. Rev. 1978, 78, 639.

(4) Johnson, B. F. G.; Rodgers, A. In The Chemistry of Metal Cluster Complexes; Shriver, D. F., Kaesz, H. D., Adams, R. D., Eds.; VCH:

New York, 1990; Chapter 6.

(5) Orpen, A. G.; Connelly, N. G. Chem. Commun. 1985, 1310.

(6) Braunstein, P.; Boag, N. M. Angew. Chem., Int. Ed. 2001, 40, 2427.

(7) Balch, A. L.; Davis, B. J.; Olmstead, M. M. J. Am. Chem. Soc. 1990, 112, 8592. Inorg. Chem. 1993, 32, 3937.

(8) (a) Hoffmann, R. Angew. Chem., Int. Ed. 1982, 21, 711. (b) Mingos, D. M. P.; Wales, D. J. Introduction to Cluster Chemistry; Prentice Hall: Englewood Cliffs, NJ, 1990.

(9) (a) Pechmann, T.; Brandt, C. D.; Werner, H. Angew. Chem., Int. Ed. 2000, 39, 3909. (b) Pechmann, T.; Brandt, C. D.; Roger, C.; Werner, H. Angew. Chem., Int. Ed. 2002, 41, 2301. (c) Pechmann, T.; Brandt, C. D.; Werner, H. Dalton Trans. 2004, 959. (d) Pechmann, T.; Brandt, C. D.; Werner, H. Chem. Eur. J. 2004, 10, 728.

(10) (a) Sauthier, M.; Le Guennic, B.; Deborde, V.; Toupet, L.; Halet, J.-F.; Réau, R. Angew. Chem., Int. Ed. 2001, 40, 228. (b) Leca, F.; Sauthier, M.; Deborde, V.; Toupet, L.; Réau, R. Chem. Eur. J. 2003, 9, 3785. (c) Leca, F.; Lescop, C.; Rodriguez-Sanz, E.; Costuas, K.; Halet, J.-F.; Réau, R. Angew. Chem., Int. Ed. 2005, 44, 4362. (d) Nohra, B.; Rodriguez-Sanz, E.; Lescop, C.; Réau, R. Chem. Eur. J. 2008, 14, 3391. coordinatively flexible, ancillary phosphine ligand in a polynuclear cluster. ${ }^{11}$ A subsequent kinetic investigation provided compelling evidence for a nondissociative mechanism for the migration of the dppe ligand in the $\mathrm{Ru}_{4}$ cluster. ${ }^{12}$ Other early examples involving phosphine fluxionality in diand trimetallic compounds have been reported, and these include the reversible migration of phosphine ligands about the triangular $\mathrm{Pt}_{3}$ face of $\left[\mathrm{Pt}_{3}\left(\mu_{3}-\mathrm{CO}\right) \mathrm{P}(\mu \text {-dppm) })_{3}\right]^{2+}$ (where $\mathrm{P}=$ monodentate phosphine, phosphite) and the "end-overend" exchange of one of the bridging diphosphine ligands in the compounds $\left[\mathrm{Ag}_{2}(\mathrm{dppm})_{3}\right]^{2+},\left[\mathrm{Ag}_{2}(\mathrm{dmpm})_{3}\right]^{2+}$, and $\left[\mathrm{Ag}_{2}(\mathrm{dppm})_{3-x}(\mathrm{dmpm})_{x}\right]^{2+}($ where $x=1,2){ }^{13-16}$

In 2000, Adams presented landmark evidence for the intramolecular exchange of the $\mathrm{PMe}_{2} \mathrm{Ph}$ ligand about platinum and ruthenium sites in the heterometallic cluster $\mathrm{PtRu}_{5^{-}}$ $\left(\mu_{6}-\mathrm{C}\right)(\mathrm{CO})_{15}\left(\mathrm{PMe} \mathrm{e}_{2} \mathrm{Ph}\right)$, as depicted in eq $1 .{ }^{17,18}$ The scrambling of the phosphine ligand about the cluster polyhedron was investigated by VT NMR measurements, and ${ }^{195} \mathrm{Pt}$ satellites for the different $\mathrm{PMe}{ }_{2} \mathrm{Ph}$ isomers were observed throughout the exchange process. This latter feature is important, as it eliminates an isomerization process arising from a ligand dissociation/association scenario. ${ }^{19} \mathrm{~A}$ mechanism involving a $\mu_{2}-\mathrm{PMe}{ }_{2} \mathrm{Ph}$ intermediate, coupled with a series of $\mathrm{CO}$ shifts across $\mathrm{Pt}-\mathrm{Ru}$ and $\mathrm{Ru}-\mathrm{Ru}$ bonds, was proposed for the dynamic isomerization that leads to the equilibration of the phosphine ligand between the different metal centers.

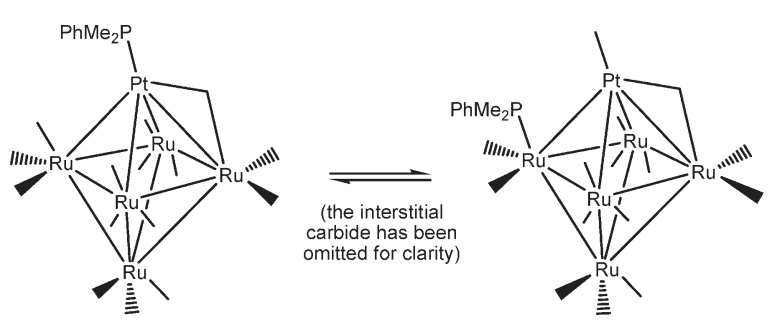

(1)

(11) Churchill, M. R.; Lashewycz, R. A.; Shapley, J. R.; Richter, S. I. Inorg. Chem. 1980, 19, 1277.

(12) Kandala, S.; Richmond, M. G. Inorg. Chem. 2006, 45, 5976.

(13) (a) Bradford, A. M.; Jennings, M. C.; Puddephatt, R. J. Organometallics 1988, 7, 792. (b) Bradford, A. M.; Douglas, G.; ManojlovićMuir, L.; Muir, K. W.; Puddephatt, R. J. Organometallics 1990, 9, 409. (14) Dean, P. A. W.; Vittal, J. J.; Srivastava, R. S. Can. J. Chem. 1987, 65,2628

(15) For some additional early reports that address the dynamic fluxionality of different pnictogen-based ligands at polynuclear systems, see: (a) Sutin, K. A.; Kolis, J. W.; Mlekuz, M.; Bougeard, P.; Sayer, B. G.; Quilliam, M. A.; Faggiani, R.; Lock, C. J. L.; McGlinchey, M. J.; Jaouen, G. Organometallics 1987, 6, 439. (b) Deeming, A. J.; Smith, M. B. Dalton Trans. 1993, 3383. (c) Yang, K.; Smith, J. M.; Bott, S. G.; Richmond, M. G. Organometallics 1993, 12, 4779. (d) Yang, K.; Bott, S. G.; Richmond, M. G. Organometallics 1994, 13, 3788. (e) Laurenczy, G.; Bondietti, G.; Ros, R.; Roulet, R. Inorg. Chim. Acta 1996, 247, 65.

(16) For a related report describing the chelate $\rightarrow$ bridge isomerization of the dppe ligands in $\mathrm{Mo}_{2} \mathrm{Br}_{4}(\mathrm{dppe})_{2}$ that proceeds via the internal rotation of the $\mathrm{Mo}_{2}$ moiety within the cubic cage of the ancillary ligands, see: Agaskar, P. A.; Cotton, F. A.; Derringer, D. R.; Powell, G. L.; Root, D. R.; Smith, T. J. Inorg. Chem. 1985, 24, 2786.

(17) (a) Adams, R. D.; Captain, B.; Fu, W.; Pellechia, P. J. Chem. Commun. 2000, 937. (b) ibid. Inorg. Chem. 2003, 42, 3111.

(18) For other relevant studies dealing with the fluxionality of a phosphine ligand at di- and polynuclear systems: (a) Ohki, Y.; Suzuki, H. Angew. Chem., Int. Ed. 2002, 41, 2994. (b) Gallo, V.; Mastrorilli, P.; Nobile, C. F.; Braunstein, P.; Englert, U. Dalton Trans. 2006, 2343. (c) Begum, N.; Das, U. K.; Hassan, M.; Hogarth, G.; Kabir, S. E.; Nordlander, E.; Rahman, M. A.; Tocher, D. A. Organometallics 2007, 26, 6462. (d) Esswein, A. J.; Veige, A. S.; Piccoli, P. M. B.; Schultz, A. J.; Nocera, D. G. Organometallics 2008, 27, 1073. 
One of us (M.G.R.) has held a long-term interest in the synthesis and mechanistic study of $\mathrm{Ru}_{3}, \mathrm{Os}_{3}$, and tetrahedrane clusters, containing rigid diphosphine ligands. ${ }^{15,20-22}$ Several of these reports have addressed the dynamic isomerization of the ancillary diphosphine ligand about the cluster core, as illustrated for the cluster compound $\mathrm{Os}_{3}(\mathrm{CO})_{10^{-}}$ (dppen) (where dppen $=(\mathrm{Z})$-1,2-bis(diphenylphosphino)ethylene) in eq 2 . This particular reaction is reversible, and the thermodynamically favored isomer contains a chelating dppen ligand with a $K_{\text {eq }}$ value of 6.9 over the temperature range $358-373 \mathrm{~K}^{21 \mathrm{a}}$ The dppen isomerization, from bridging to chelating, is unaffected by added $\mathrm{CO}$, and the activation parameters for the forward and reverse reactions indicate an ordered transition state. The reaction kinetics are consistent with a nondissociative scenario for this rearrangement, requiring, at a minimum, the formal site exchange of at least one phosphine and one $\mathrm{CO}$ across an Os-Os bond, presumably by way of a transient $\mu_{2}$-phosphine $/ \mu_{2}$-CO species.

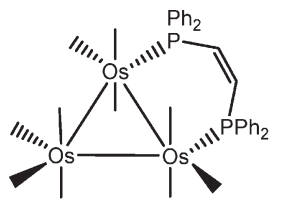

$1,2-\mathrm{Os}_{3}(\mathrm{CO})_{10}(\mathrm{dppen})$

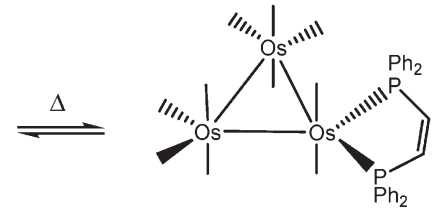

$1,1-\mathrm{Os}_{3}(\mathrm{CO})_{10}(\mathrm{dppen})$
In order to establish the influence that the differences between closely related diphosphine ligands have on the reactivity of the isomeric $\mathrm{Os}_{3}(\mathrm{CO})_{10}(\mathrm{P}-\mathrm{P})$ clusters, we have investigated the reaction of 1,2-bis(diphenylphosphino)benzene (dppbz) and 1,2-bis(diphenylphosphino)tetrafluorobenzene $\left(\mathrm{dppbzF}_{4}\right)$ with the triosmium cluster $1,2-\mathrm{Os}_{3}-$ $(\mathrm{CO})_{10}(\mathrm{MeCN})_{2}(\mathbf{1})$. The dppbz ligand reacts with 1,2-Os $3^{-}$ $(\mathrm{CO})_{10}(\mathrm{MeCN})_{2}$ to furnish bridged $1,2-\mathrm{Os}_{3}(\mathrm{CO})_{10}(\mathrm{dppbz})$ as the kinetic product of ligand substitution, and the kinetics for isomerization to the corresponding chelated isomer, 1,1$\mathrm{Os}_{3}(\mathrm{CO})_{10}(\mathrm{dppbz})$, have been followed by UV-vis spectroscopy. In contrast to the reaction of $\mathbf{1}$ with dppbz, the reaction between 1 and $\mathrm{dppbzF}_{4}$ affords chelated $1,1-\mathrm{Os}_{3}(\mathrm{CO})_{10^{-}}$ $\left(\mathrm{dppbzF}_{4}\right)$ as the sole observable product. Presumably, the bridged isomer is again formed but rearranges rapidly to the chelated isomer.

We have performed DFT calculations, in order to explore the effect that different diphosphine ligands have on the thermodynamic and kinetic stabilities of the bridged and chelated isomers in the $\mathrm{Os}_{3}(\mathrm{CO})_{10}(\mathrm{P}-\mathrm{P})$ clusters. In the course of establishing the mechanism for the rearrangement

(19) Jesson, J. P.; Muetterties, E. L. In Dynamic Nuclear Magnetic Resonance Spectroscopy; Jackman, L. M., Cotton, F. A., Eds.; Academic Press: New York, 1975; Chapter 8.

(20) For $\mathrm{Ru}_{3}$ clusters: (a) Shen, H.; Bott, S. G.; Richmond, M. G. Organometallics 1995, 14, 4625. (b) Bott, S. G.; Shen, H.; Senter, R. A.; Richmond, M. G. Organometallics 2003, 22, 1953. (c) Bott, S. G.; Shen, H.; Richmond, M. G. J. Organomet. Chem. 2004, 689, 3426. 2005, 690, 3838. (d) Bott, S. G.; Shen, H.; Huang, S.-H.; Richmond, M. G. J. Organomet. Chem. 2008, 693, 2327.

(21) For Os $\mathrm{O}_{3}$ clusters: (a) Watson, W. H.; Wu, G.; Richmond, M. G. Organometallics 2005, 24, 5431. (b) Watson, W. H.; Wu, G.; Richmond, M. G. Organometallics 2006, 25, 930. (c) Watson, W. H.; Poola, B.; Richmond, M. G. J. Organomet. Chem. 2006, 691, 4676. (d) Watson, W. H.; Poola, B.; Richmond, M. G. Polyhedron 2007, 26, 3585.

(22) For tetrahedrane clusters: (a) Bott, S. G.; Yang, K.; Talafuse, K. A.; Richmond, M. G. Organometallics 2003, 22, 1383. (b) Bott, S. G.; Yang, K.; Richmond, M. G. J. Organomet. Chem. 2005, 690, 3067; 2006, 691,3771 (c) Watson, W. H.; Bodige, S. G.; Ejsmont, K.; Liu, J.; Richmond, M. G. J. Organomet. Chem. 2006, 691, 3609. of bridged to chelated isomers, we investigated the nature of the preferred pathway that is responsible for nondissociative ligand isomerization in this genre of clusters.

\section{Experimental Section}

General Methods. The parent cluster $\mathrm{Os}_{3}(\mathrm{CO})_{12}$ was prepared from $\mathrm{OsO}_{4}$ and $\mathrm{CO},{ }^{23}$ and this cluster was used in the preparation of the bis(acetonitrile) cluster $1,2-\mathrm{Os}_{3}(\mathrm{CO})_{10}(\mathrm{MeCN})_{2}{ }^{24}$ The $\mathrm{dppbzF}_{4}$ ligand was synthesized from 1,2-dibromotetrafluorobenzene and $\mathrm{Ph}_{2} \mathrm{PCl}$ according to the procedure of Meek. ${ }^{25}$ The $\mathrm{OsO}_{4}$ used in our studies was purchased from Engelhard Chemical Co., and the chemicals $\mathrm{Me}_{3} \mathrm{NO} \cdot x \mathrm{H}_{2} \mathrm{O}$, dppbz, 1,2-dibromotetrafluorobenzene, chlorodiphenylphosphine, and BuLi (2.5 $\mathrm{M}$ in hexanes) were purchased from Aldrich Chemical Co. The anhydrous $\mathrm{Me}_{3} \mathrm{NO}$ employed in our studies was obtained from $\mathrm{Me}_{3} \mathrm{NO} \cdot x \mathrm{H}_{2} \mathrm{O}$, after the waters of hydration were azeotropically removed under reflux, using benzene as a solvent. All reaction solvents were distilled from a suitable drying agent under argon or obtained from an Innovative Technology (IT) solvent purification system. When not in use, all purified solvents were stored in Schlenk storage vessels equipped with high-vacuum Teflon stopcocks. ${ }^{26}$ The NMR solvents $\mathrm{CDCl}_{3}$ and $\mathrm{C}_{6} \mathrm{D}_{6}$ were purified by bulb-to-bulb distillation from $\mathrm{P}_{2} \mathrm{O}_{5}$ and sodium/benzophenone ketyl, respectively. Combustion analyses were performed by Atlantic Microlab, Norcross, GA.

The IR spectra were recorded on a Nicolet 6700 FT-IR spectrometer in amalgamated $\mathrm{NaCl}$ cells having a $0.1 \mathrm{~mm}$ path length, while the quoted ${ }^{1} \mathrm{H}$ NMR data were recorded at 400 and $500 \mathrm{MHz}$ on Varian VXR-400 and VXR-500 spectrometers, respectively. The ${ }^{31} \mathrm{P}$ NMR spectra were recorded at $202 \mathrm{MHz}$ on the latter spectrometer. These data were collected in the proton-decoupled mode and are referenced to external $\mathrm{H}_{3} \mathrm{PO}_{4}$ $(85 \%)$, whose chemical shift was set at $\delta 0$.

Preparation of $1,2-\mathrm{Os}_{3}(\mathrm{CO})_{10}(\mathrm{dppbz})$ from $1,2-\mathrm{Os}_{3}(\mathrm{CO})_{10^{-}}$ $(\mathrm{MeCN})_{2}$ and dppbz. To $0.25 \mathrm{~g}(0.27 \mathrm{mmol})$ of $1,2-\mathrm{Os}_{3}(\mathrm{CO})_{10^{-}}$ $(\mathrm{MeCN})_{2}$ in a Schlenk tube was added $0.14 \mathrm{~g}(0.31 \mathrm{mmol})$ of dppbz, followed by $30 \mathrm{~mL}$ of $\mathrm{CH}_{2} \mathrm{Cl}_{2}$ via syringe. The solution was stirred for $3 \mathrm{~h}$ at room temperature and then examined by TLC analysis $\left(1 / 1 \mathrm{CH}_{2} \mathrm{Cl}_{2}\right.$ /hexane), which revealed the consumption of the starting cluster, a trace amount of unreacted $\operatorname{dppbz}\left(R_{\mathrm{f}}=0.53\right)$, and a yellow spot $\left(R_{\mathrm{f}}=0.48\right)$ corresponding primarily to $\mathbf{2}(78 \%)$, along with minor amounts of $\mathbf{3}(20 \%)$ and 4 (ca. $2 \%$ ), whose presence was established by NMR spectroscopy. The ternary cluster mixture, composed of $\mathbf{2 - 4}$, could not be separated into individual components; these products were isolated as a mixture by flash-column chromatography over alumina at $0{ }^{\circ} \mathrm{C}$, using the aforementioned eluent. Spectroscopic data for cluster $2^{27}$ are as follows. IR $\left(\mathrm{CH}_{2} \mathrm{Cl}_{2}\right): v(\mathrm{CO}) 2092(\mathrm{~s})$, $2041(\mathrm{~m}), 2013(\mathrm{~s}), 2004(\mathrm{~m}), 1973(\mathrm{w}) \mathrm{cm}^{-1} .{ }^{1} \mathrm{H} \mathrm{NMR}\left(\mathrm{CDCl}_{3}\right)$ : $\delta 6.78-7.50\left(\mathrm{~m}\right.$, aryl). ${ }^{31} \mathrm{P}$ NMR $\left(\mathrm{CDCl}_{3}\right): \delta 6.41(\mathrm{~s})$.

Isomerization of $1,2-\mathrm{Os}_{3}(\mathrm{CO})_{10}(\mathrm{dppbz})$ to $1,1-\mathrm{Os}_{3}(\mathrm{CO})_{10^{-}}$ (dppbz) under CO. The above cluster mixture (ca. $0.33 \mathrm{~g}$ ) was heated in toluene at $60{ }^{\circ} \mathrm{C}$ under $1 \mathrm{~atm}$ of $\mathrm{CO}$ for $24 \mathrm{~h}$, after which time ${ }^{31} \mathrm{P}$ NMR analysis of the solution revealed the presence of only cluster 3. The solvent was removed under vacuum and the residue chromatographed over alumina using a $1 / 1 \mathrm{CH}_{2} \mathrm{Cl}_{2} /$ hexane mixture. The crude product was recrystallized from $\mathrm{CH}_{2} \mathrm{Cl}_{2}$ and hexane at $5{ }^{\circ} \mathrm{C}$ to afford 3 as a dark yellow solid. Yield: $0.31 \mathrm{~g}(94 \%)$. IR $\left(\mathrm{CH}_{2} \mathrm{Cl}_{2}\right): v(\mathrm{CO}) 2094(\mathrm{~s})$,

(23) Drake, S. R.; Loveday, P. A. Inorg. Synth. 1990, 28, 230.

(24) Nicholls, J. N.; Vargas, M. D. Inorg. Synth. 1989, 26, 289.

(25) Eller, P. G.; Meek, D. W. J. Organomet. Chem. 1970, 22, 631.

(26) Shriver, D. F. The Manipulation of Air-Sensitive Compounds; McGraw-Hill: New York, 1969.

(27) A relatively pure IR spectrum of cluster $\mathbf{2}$ was obtained after suitable spectral subtraction of clusters $\mathbf{3}$ and $\mathbf{4}$ from the initial ternary cluster mixture. 
Table 1. X-ray Crystallographic Data and Processing Parameters for the dppbz-Substituted Clusters $2 \cdot \mathrm{CH}_{2} \mathrm{Cl}_{2}, \mathbf{3}$, and $_{4} \cdot \mathrm{CH}_{2} \mathrm{Cl}_{2}$

\begin{tabular}{|c|c|c|c|}
\hline & $\mathbf{2} \cdot \mathrm{CH}_{2} \mathrm{Cl}_{2}$ & 3 & $4 \cdot \mathrm{CH}_{2} \mathrm{Cl}_{2}$ \\
\hline CCDC entry no. & 770699 & 770697 & 770702 \\
\hline cryst syst & triclinic & monoclinic & orthorhombic \\
\hline space group & $P \overline{1}$ & $P 2_{1} / c$ & $P b c a$ \\
\hline$a, \AA$ & $11.9406(3)$ & $10.983(2)$ & $21.745(2)$ \\
\hline$b, \AA$ & $13.2173(4)$ & $20.218(3)$ & $16.774(2)$ \\
\hline$c, \AA$ & $15.0648(4)$ & $17.530(3)$ & $21.934(2)$ \\
\hline$\alpha, \operatorname{deg}$ & 86.091(1) & & \\
\hline$\beta, \operatorname{deg}$ & $70.006(1)$ & $96.856(3)$ & \\
\hline$\gamma$, deg & $66.423(1)$ & & \\
\hline$V, \AA^{3}$ & 2041.2(1) & $3865(1)$ & $8001(1)$ \\
\hline mol formula & $\mathrm{C}_{41} \mathrm{H}_{26} \mathrm{Cl}_{2} \mathrm{O}_{10} \mathrm{Os}_{3} \mathrm{P}_{2}$ & $\mathrm{C}_{40} \mathrm{H}_{24} \mathrm{O}_{10} \mathrm{Os}_{3} \mathrm{P}_{2}$ & $\mathrm{C}_{40} \mathrm{H}_{26} \mathrm{Cl}_{2} \mathrm{O}_{9} \mathrm{Os}_{3} \mathrm{P}_{2}$ \\
\hline fw & 1382.06 & 1297.13 & 1354.05 \\
\hline formula units per cell $(Z)$ & 2 & 4 & 8 \\
\hline$D_{\text {calcd }}, \mathrm{Mg} / \mathrm{m}^{3}$ & 2.249 & 2.229 & 2.248 \\
\hline$\lambda(\operatorname{Mo~K\alpha }), \AA$ & 0.71073 & 0.71073 & 0.71073 \\
\hline$\mu, \mathrm{mm}^{-1}$ & 9.581 & 9.979 & 9.773 \\
\hline abs cor & semiempirical from equivalents & empirical from equivalents & semiempirical \\
\hline$F(000)$ & 1288 & 2408 & 5040 \\
\hline cryst size, $\mathrm{mm}$ & $0.11 \times 0.08 \times 0.06$ & $0.28 \times 0.14 \times 0.03$ & $0.24 \times 0.17 \times 0.06$ \\
\hline abs cor factor & $0.5971 / 0.4188$ & $0.9942 / 0.3008$ & $0.5917 / 0.2026$ \\
\hline total no. of rflns & 24301 & 32839 & 14706 \\
\hline no. of indep rflns & 8375 & 9099 & 14832 \\
\hline no. of data/residuals/params & $8375 / 0 / 523$ & $9099 / 0 / 496$ & $14832 / 4 / 516$ \\
\hline $\mathrm{R}^{a}(I \geq 2 \sigma(I))$ & 0.0140 & 0.0301 & 0.0388 \\
\hline $\mathrm{wR} 2^{b}$ & 0.0322 & 0.0492 & 0.0697 \\
\hline GOF on $F^{2}$ & 1.012 & 0.905 & 1.028 \\
\hline $\max , \min \Delta \rho, \mathrm{e} / \AA^{3}$ & $1.114,-0.402$ & $0.902,-1.218$ & $2.434,-2.301$ \\
\hline
\end{tabular}

$2040(\mathrm{~m}), 2011(\mathrm{~s}), 2001(\mathrm{~m}), 1971(\mathrm{w}) \mathrm{cm}^{-1} .{ }^{1} \mathrm{H}$ NMR $\left(\mathrm{C}_{6} \mathrm{D}_{6}\right): \delta$ 6.78 (unresolved multiplet, $2 \mathrm{H}$, aryl platform), 6.94 (t, $4 \mathrm{H}$, para, aryl, $\left.J_{\mathrm{H}-\mathrm{H}}=7.3 \mathrm{~Hz}\right), 7.04\left(\mathrm{t}, 8 \mathrm{H}\right.$, meta, aryl, $\left.J_{\mathrm{H}-\mathrm{H}}=7.3 \mathrm{~Hz}\right)$, 7.30 (unresolved multiplet, $2 \mathrm{H}$, aryl platform), 7.49 (bm, $8 \mathrm{H}$, ortho, aryl). ${ }^{31} \mathrm{P}$ NMR $\left(\mathrm{C}_{6} \mathrm{D}_{6}\right): \delta 26.32$ (s). Anal. Calcd (found) for $\mathrm{C}_{40} \mathrm{H}_{24} \mathrm{O}_{10} \mathrm{Os}_{3} \mathrm{P}_{2} \cdot{ }^{1} /{ }_{2} \mathrm{CH}_{2} \mathrm{Cl}_{2}$ : C, 36.31 (36.19); $\mathrm{H}, 1.88$ (1.75).

Photolysis of 1,1-Os $3(\mathrm{CO})_{10}(\mathrm{dppbz})$ To Give $\mathrm{HOs}_{3}(\mathrm{CO})_{9}[\mu$ 1,2-PhP $\left.\left(\mathbf{C}_{6} \mathbf{H}_{4}-\eta^{1}\right) \mathbf{C}_{6} \mathbf{H}_{4} \mathbf{P P h}_{2}\right]$. A small Schlenk tube was charged with $0.10 \mathrm{~g}(0.077 \mathrm{mmol})$ of $\mathbf{3}$ and $25 \mathrm{~mL}$ of toluene, after which the vessel was sealed and subjected to three free$\mathrm{ze}$-pump-thaw degas cycles. The vessel was then irradiated $(366 \mathrm{~nm})$ at room temperature for a period of 5 days. The $\mathrm{CO}$ that accompanies the formation of $\mathbf{4}$ was periodically removed by additional freeze-pump - thaw degas cycles, in order to drive the reaction to completion. At the end of the photolysis, the solution was concentrated under vacuum; the residue was passed over a short pad of alumina, using $1 / 1 \mathrm{CH}_{2} \mathrm{Cl}_{2} /$ hexane as the eluent, to furnish a yellow solid. Recrystallization of 4 from $\mathrm{CH}_{2} \mathrm{Cl}_{2}$ /benzene afforded the desired product in $88 \%$ yield (86 mg). IR ( $\left.\mathrm{CH}_{2} \mathrm{Cl}_{2}\right): v(\mathrm{CO}) 2075$ (s), 2038 (vs), 2013 (s), 1997 (s), $1967(\mathrm{~m}) \mathrm{cm}^{-1} .{ }^{1} \mathrm{H}$ NMR $\left(\mathrm{C}_{6} \mathrm{D}_{6}\right): \delta-16.43$ (dd, hydride, $J_{\mathrm{P}-\mathrm{H}}=12.5$ and $\left.16.0 \mathrm{~Hz}\right), 6.68-7.52(\mathrm{~m}, 22 \mathrm{H}$, aryl $), 8.36(\mathrm{dd}$, $1 \mathrm{H}$, metalated aryl, $J_{\mathrm{H}-\mathrm{H}}=2.5$ and $\left.6.5 \mathrm{~Hz}\right) .{ }^{31} \mathrm{P}$ NMR $\left(\mathrm{C}_{6} \mathrm{D}_{6}\right)$ : $\delta 28.62\left(\mathrm{~d}, J_{\mathrm{P}-\mathrm{P}}=13.3 \mathrm{~Hz}\right), 39.54\left(\mathrm{~d}, J_{\mathrm{P}-\mathrm{P}}=13.3 \mathrm{~Hz}\right)$. Anal. Calcd (found) for $\mathrm{C}_{40} \mathrm{H}_{24} \mathrm{O}_{10} \mathrm{Os}_{3} \mathrm{P}_{2} \cdot{ }^{1}{ }_{2} \mathrm{C}_{6} \mathrm{H}_{6}$ : C, 38.53 (38.15); H, $2.06(2.50)$.

Reaction of 1,2-Os ${ }_{3}(\mathrm{CO})_{10}(\mathrm{MeCN})_{2}$ with $\mathrm{dppbzF}_{4}$ To Give 1,1$\mathrm{Os}_{3}(\mathbf{C O})_{10}\left(\mathbf{d p p b z F}_{4}\right)$. To $0.20 \mathrm{~g}(0.21 \mathrm{mmol})$ of $1,2-\mathrm{Os}_{3}(\mathrm{CO})_{10^{-}}$ $(\mathrm{MeCN})_{2}$ in $50 \mathrm{~mL}$ of benzene was added $0.12 \mathrm{~g}(0.23 \mathrm{mmol})$ of $\mathrm{dppbzF}_{4}$ under argon flush. The solution was stirred at room temperature and monitored by TLC, which confirmed the consumption of the starting cluster and the presence of a yellow spot ascribed to cluster $\mathbf{6}\left(R_{\mathrm{f}}=0.79\right.$ in $1 / 1 \mathrm{CH}_{2} \mathrm{Cl}_{2} /$ hexane $)$ after ca. $1 \mathrm{~h}$. The solvent was removed under vacuum and the desired product purified by chromatography over silica gel employing $1 / 1 \mathrm{CH}_{2} \mathrm{Cl}_{2} /$ hexane as the mobile phase. The isolated product was recrystallized from $\mathrm{CH}_{2} \mathrm{Cl}_{2} /$ hexane at $5{ }^{\circ} \mathrm{C}$ to furnish $0.25 \mathrm{~g}$ $(85 \%)$ of analytically pure 6 . IR $\left(\mathrm{CH}_{2} \mathrm{Cl}_{2}\right): v(\mathrm{CO}) 2095$ (s), 2046 (s), 2010 (vs), $1992(\mathrm{~m}), 1975(\mathrm{~m}), 1962$ (m), $1927(\mathrm{w}) \mathrm{cm}^{-1} \cdot{ }^{1} \mathrm{H}$ $\operatorname{NMR}\left(\mathrm{C}_{6} \mathrm{D}_{6}\right): \delta 7.20\left(\mathrm{t}, 4 \mathrm{H}\right.$, para, $\left.J_{\mathrm{H}-\mathrm{H}}=8.0 \mathrm{~Hz}\right), 7.34(\mathrm{dt}, 8 \mathrm{H}$, meta, $\left.J_{\mathrm{H}-\mathrm{H}}=8.0 \mathrm{~Hz}, J_{\mathrm{P}-\mathrm{H}}=2.7 \mathrm{~Hz}\right), 7.76(\mathrm{dd}, 8 \mathrm{H}$, ortho, $\left.J_{\mathrm{P}-\mathrm{H}}=11.5 \mathrm{~Hz}, J_{\mathrm{H}-\mathrm{H}}=8.0 \mathrm{~Hz}\right) .{ }^{31} \mathrm{P} \mathrm{NMR}\left(\mathrm{CDCl}_{3}\right): \delta 34.00$ (s). Anal. Calcd (found) for $\mathrm{C}_{40} \mathrm{H}_{20} \mathrm{~F}_{4} \mathrm{O}_{10} \mathrm{Os}_{3} \mathrm{P}_{2}$ : $\mathrm{C}, 35.09$ (34.82); H, 1.47 (1.56).

Photolysis of $1,1-\mathrm{Os}_{3}(\mathrm{CO})_{10}\left(\mathrm{dppbzF}_{4}\right)$ To Give $\mathrm{HOs}_{3}(\mathrm{CO})_{9}[\mu$ 1,2-PhP( $\left.\left.\mathbf{C}_{\mathbf{6}} \mathbf{H}_{\mathbf{4}}-\boldsymbol{\eta} \mathbf{\eta}^{\mathbf{1}}\right) \mathbf{C}_{\mathbf{6}} \mathbf{F}_{\mathbf{4}} \mathbf{P} \mathbf{P h}_{\mathbf{2}}\right]$. A $50 \mathrm{mg}(0.037 \mathrm{mmol})$ portion of 6 was charged to a NMR tube equipped with a J. Young valve, followed by $0.7 \mathrm{~mL}_{\text {of }} \mathrm{C}_{6} \mathrm{D}_{6}$. The solution was evacuated via two freeze-pump-thaw degas cycles, and the NMR tube was irradiated at $366 \mathrm{~nm}$ at room temperature for a period of $24 \mathrm{~h}$. The liberated $\mathrm{CO}$ was removed by three periodic freezepump-thaw cycles during the course of the reaction. Once the NMR analysis confirmed the disappearance of $\mathbf{6}$, the irradiation was terminated and the solvent removed. The desired product was subsequently isolated by column chromatography over silica gel using $1 / 1 \mathrm{CH}_{2} \mathrm{Cl}_{2} /$ hexane, after which the product was recrystallized from hexane/benzene to afford 7 in $90 \%$ yield (44 mg). IR ( $\left.\mathrm{CH}_{2} \mathrm{Cl}_{2}\right): v(\mathrm{CO}) 2085$ (s), 2025 (s), 2002 (vs), 1996 (m), $1951(\mathrm{~m}) \mathrm{cm}^{-1} .{ }^{1} \mathrm{H}$ NMR $\left(\mathrm{C}_{6} \mathrm{D}_{6}\right): \delta-16.13$ (dd, hydride, $J_{\mathrm{P}-\mathrm{H}}=13.8$ and $\left.14.2 \mathrm{~Hz}\right), 6.88(\mathrm{bm}, 2 \mathrm{H}$, metalated aryl), 6.97-7.16 (m, 10H), $7.56(\mathrm{~m}, 3 \mathrm{H}), 7.68(\mathrm{~m}, 2 \mathrm{H}), 8.05(\mathrm{bt}, 1 \mathrm{H}$, metalated aryl, $\left.J_{\mathrm{H}-\mathrm{H}}=7.5 \mathrm{~Hz}\right), 8.37\left(\mathrm{~m}, 1 \mathrm{H}\right.$, metalated aryl). ${ }^{28}$ ${ }^{31} \mathrm{P}$ NMR $\left(\mathrm{CDCl}_{3}\right): \delta 41.17$ (b, unresolved fluorine coupling), 44.43 (b, unresolved fluorine coupling). Anal. Calcd (found) for $\mathrm{C}_{39} \mathrm{H}_{20} \mathrm{~F}_{4} \mathrm{O}_{9} \mathrm{Os}_{3} \mathrm{P}_{2} .{ }^{1} /{ }_{2} \mathrm{C}_{6} \mathrm{H}_{6}: \mathrm{C}, 36.52$ (37.01); H, 1.67 (2.18).

Isomerization Kinetics. The conversion $\mathbf{2} \rightarrow \mathbf{3}$ was investigated by $\mathrm{UV}-$ vis spectroscopy in quartz $\mathrm{UV}-$ visible cells $(1.0 \mathrm{~cm}$ width) that were equipped with a high-vacuum Teflon stopcock, to facilitate handling on the vacuum line. Samples of $\mathbf{2}$ in toluene solution were purged with $\mathrm{CO}$ at room temperature immediately before the start of each kinetic experiment, in order to suppress the formation of the hydride cluster 4 . The experiments conducted at 6.8 and $34 \mathrm{~atm}$ of $\mathrm{CO}$ were carried out in a carbon-steel $300 \mathrm{~mL}$ autoclave, where the reaction pressure was controlled by a Tescom pressure regulator. The autoclave was equipped with a tip tube that enabled sample removal for UV-vis analysis while maintaining constant CO pressure. The Hewlett-Packard 8452A

(28) The quoted $J_{\mathrm{P}-\mathrm{H}}$ values for the bridging hydride were determined by spectral simulation using the program gNMR. 


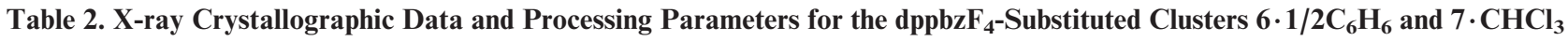

\begin{tabular}{|c|c|c|}
\hline & $\mathbf{6} \cdot{ }^{1} /{ }_{2} \mathrm{C}_{6} \mathrm{H}_{6}$ & $7 \cdot \mathrm{CHCl}_{3}$ \\
\hline CCDC entry no. & 770698 & 770701 \\
\hline $\begin{array}{l}\text { cryst syst } \\
\text { space group }\end{array}$ & $P \overline{1}$ & $\begin{array}{l}\text { monoclinic } \\
P 2_{1} / n\end{array}$ \\
\hline$a, \AA$ & $12.1322(5)$ & $11.4132(6)$ \\
\hline$b, \AA$ & $17.5733(8)$ & $19.109(1)$ \\
\hline$c, \AA$ & $21.598(1)$ & $18.870(1)$ \\
\hline$\alpha, \operatorname{deg}$ & $94.371(1)$ & \\
\hline$\beta, \operatorname{deg}$ & $101.218(1)$ & $95.543(1)$ \\
\hline$\gamma, \operatorname{deg}$ & $106.671(1)$ & \\
\hline$V, \AA^{3}$ & $4284.0(3)$ & $4096.0(4)$ \\
\hline mol formula & $\mathrm{C}_{43} \mathrm{H}_{23} \mathrm{~F}_{4} \mathrm{O}_{10} \mathrm{Os}_{3} \mathrm{P}_{2}$ & $\mathrm{C}_{40} \mathrm{H}_{20} \mathrm{Cl}_{3} \mathrm{~F}_{4} \mathrm{O}_{9} \mathrm{Os}_{3} \mathrm{P}_{2}$ \\
\hline & 1408.15 & 1459.45 \\
\hline formula units per cell $(Z)$ & 4 & 4 \\
\hline$D_{\text {calcd }}, \mathrm{Mg} / \mathrm{m}^{3^{+}}$ & 2.183 & 2.367 \\
\hline$\lambda(\operatorname{Mo~K} \alpha), \AA$ & 0.71073 & 0.71073 \\
\hline$\mu, \mathrm{mm}^{-1}$ & 9.025 & 9.631 \\
\hline abs cor & semiempirical from equivalents & semiempirical from equivalents \\
\hline$F(000)$ & 2620 & 2708 \\
\hline cryst size, $\mathrm{mm}$ & $0.27 \times 0.26 \times 0.06$ & $0.23 \times 0.11 \times 0.07$ \\
\hline abs cor factor & $0.6055 / 0.1927$ & $0.5096 / 0.2371$ \\
\hline total no. of rflns & 53669 & 48738 \\
\hline no. of indep rflns & 18867 & 8685 \\
\hline no. of data/residuals/params & $18867 / 187 / 1128$ & $8685 / 0 / 547$ \\
\hline $\mathrm{R}^{a}(I \geq 2 \sigma(I))$ & 0.0240 & 0.0238 \\
\hline $\mathrm{wR} 2^{b}$ & 0.0287 & 0.0300 \\
\hline $\mathrm{GOF}$ on $F^{2}$ & 1.026 & 1.041 \\
\hline $\max , \min \Delta \rho, \mathrm{e} / \AA^{3}$ & $1.779,-1.696$ & $3.353,-1.123$ \\
\hline
\end{tabular}

diode array spectrometer employed in our studies was configured with a custom VT cell holder, which was connected to a Neslab RTE7 constant-temperature circulator. The quoted reaction temperatures are considered to be accurate to within $\pm 0.5 \mathrm{~K}$. The progress of the isomerization reactions, conducted at $1 \mathrm{~atm}$ of $\mathrm{CO}$, was monitored by following the optical changes of the $365 \mathrm{~nm}$ band as a function of time for at least 4-6 halflives, while those reactions carried out under higher $\mathrm{CO}$ pressure were examined out to 3 half-lives. The UV-vis derived rate constants, quoted in Table 3, were determined by nonlinear regression analysis, using a single-exponential function, with the initial $\left(A_{0}\right)$ and final $\left(A_{\infty}\right)$ absorbance values and the rate constant $(k)$ treated as free variables in the calculation. ${ }^{29}$ The activation parameters for the isomerization $\mathbf{2} \rightarrow \mathbf{3}$ were calculated from a plot of $\ln (k / T)$ versus $T^{-1},{ }^{30}$ with the error limits representing the deviation of the data points about the leastsquares line of the Eyring plot.

X-ray Diffraction Data for Clusters 2-6. Single crystals of the cluster compounds $\mathbf{2 - 4}$, suitable for $\mathrm{X}$-ray diffraction analyses, were grown from $\mathrm{CH}_{2} \mathrm{Cl}_{2}$ and hexane, while $\mathrm{X}$-ray-quality crystals of 6 and 7 were grown from benzene/hexane and $\mathrm{CHCl}_{3} /$ hexane, respectively. With the exception of cluster 3 , whose X-ray data were collected at TCU on a Bruker SMART 1000 CCD-based diffractometer at 213(2) K, all of the other structures were collected at UNT on a Bruker X8 APEX CCD diffractometer at $100(2) \mathrm{K}$. The frames were integrated with the available SAINT ${ }^{31}$ (TCU) and APEX2 ${ }^{32}$ (UNT) software packages, using a narrow-frame algorithm; the structures were solved and refined using the SHELXTL program package. ${ }^{33}$

(29) The rate calculations were performed by using the equation $A(t)$ $=A_{\infty}+\Delta A e^{-k t}$ with the aid of the commercially available program Origin6.0.

(30) Carpenter, B. K. Determination of Organic Reaction Mechanisms; Wiley-Interscience: New York, 1984.

(31) Saint Version 6.02; Bruker Advanced Analytical X-ray Systems, Inc., 1997-1999.

(32) APEX2 Version 2.14; Bruker Advanced Analytical X-ray Systems, Inc., Madison, WI, 2007.

(33) SHELXTL Version 5.1; Bruker Advanced Analytical X-ray Systems, Inc., Madison, WI, 1998.
The molecular structures were checked using PLATON, ${ }^{34}$ and the non-hydrogen atoms were refined anisotropically, except where otherwise noted. All hydrogen atoms were assigned calculated positions and allowed to ride on the attached carbon atom. The cluster $\mathbf{4} \cdot \mathrm{CH}_{2} \mathrm{Cl}_{2}$ was found to be twinned in the first domain by $178.1^{\circ}$ about the reciprocal axis $-0.010,1.000,0.008$ (twin ratio 0.625:0.375). The structure was refined using unmerged data in HKL5 format and contained a disordered solvent. These drawbacks affected the quality of the collected $\mathrm{X}$-ray data and prevented the accurate location of the bridging hydride group that is assumed to span the Os(2)-Os(3) vector in $4 \cdot \mathrm{CH}_{2} \mathrm{Cl}_{2}$. the cluster $6 \cdot{ }^{1} /{ }_{2} \mathrm{C}_{6} \mathrm{H}_{6}$ exists as two independent 1,1 $\mathrm{Os}_{3}(\mathrm{CO})_{10}\left(\mathrm{dppbzF}_{4}\right)$ molecules in the asymmetric unit of the triclinic cell $\left(Z^{\prime}=2\right)$. Disorder was found for the phenyl groups on the atoms P2 and P3 and the benzene solvent molecules located on inversion centers $1 f$ and $1 e$. The disordered parts were refined accordingly with distance restraints to simulate the hexagonal shape of the aromatic rings. Tables 1 and 2 summarize the pertinent $X$-ray data and processing parameters for these triosmium clusters.

Computational Methodology. All calculations were performed with the Gaussian 03 package of programs. ${ }^{35}$ The calculations were carried out with the B3LYP functional, which is comprised of Becke's linear combination of three functionals ${ }^{36}$ and the correlation functional of Lee, Yang, and Parr. ${ }^{37}$ The Os atoms were described by Stuttgart-Dresden effective core potentials and the SDD basis set. ${ }^{38}$ The D95* basis set was used for the P, $\mathrm{O}, \mathrm{C}$, and $\mathrm{H}$ atoms. ${ }^{39}$

(34) Spek, A. L. J. Appl. Crystallogr. 2003, 36, 7.

(35) Frisch, M. J. et al. Gaussian 03, Revision E.01; Gaussian, Inc., Pittsburgh, PA, 2003.

(36) Becke, A. D. Phys. Rev. A 1988, 38, 3098

(37) (a) Lee, C.; Yang, W.; Parr, R. G. Phys. Rev. B 1988, 37, 785. (b) Miehlich, B.; Savin, A.; Stoll, H.; Preuss, H. Chem. Phys. Lett. 1989, 157, 200.

(38) Dolg, M. In Modern Methods and Algorithms of Quantum Chemistry; Grotendorst, J., Ed.; John von Neumann Institute for Computing: Jülich, 2000; Vol. 1, p 479.

(39) Dunning, T. H., Jr.; Hay, P. J. In Modern Theoretical Chemistry; Schaefer, H. F., III, Ed.; Plenum: New York, 1976; Vol. 3, pp 1-28. 




2
Scheme 1



Geometries were fully optimized, and analytical second derivatives were evaluated at each stationary point, to establish whether the geometry was an energy minimum (no imaginary frequencies) or a transition structure (one imaginary frequency). The computed frequencies were used to make zero-point and thermal corrections to the electronic energies.

\section{Results and Discussion}

I. Diphosphine Bridging and Chelation in the Reaction of 1,2-Os ${ }_{3}(\mathrm{CO})_{10}(\mathrm{MeCN})_{2}$ with dppbz. The labile cluster 1,2$\mathrm{Os}_{3}(\mathrm{CO})_{10}(\mathrm{MeCN})_{2}$ reacts rapidly with the diphosphine ligand dppbz at room temperature, to furnish the corresponding diphosphine-bridged cluster 1,2-Os ${ }_{3}(\mathrm{CO})_{10^{-}}$ $(\mathrm{dppbz})(2)$ as the major product. The yield of crude product was $78 \%$, as assessed by ${ }^{31} \mathrm{P}$ NMR analysis of an aliquot of the reaction before purification. ${ }^{40}$ Accompanying 2 in the reaction mixture were the isomeric chelated cluster $1,1-\mathrm{Os}_{3}$ $(\mathrm{CO})_{10}(\mathrm{dppbz})(3)$ and the hydride cluster $\mathrm{HOs}_{3}(\mathrm{CO})_{9}[\mu-1,2-$ $\left.\mathrm{PhP}\left(\mathrm{C}_{6} \mathrm{H}_{4}-\eta^{1}\right) \mathrm{C}_{6} \mathrm{H}_{4} \mathrm{PPh}_{2}\right](4)$, which were formed in $20 \%$ and $2 \%$ yields, respectively. These two minor products both result from the isomerization of $\mathbf{2}$ to $\mathbf{3}$. Decarbonylation of the latter cluster leads to ortho metalation and the formation of 4 (vide infra). The relationship between these dppbzsubstituted clusters is summarized in Scheme 1.

TLC analysis of the crude reaction mixture revealed the presence of only one spot for the three products; therefore, the ternary mixture was isolated by flash-column chromatography and characterized in solution as an aggregate. The spectroscopic properties of $\mathbf{2}$ are consistent with its formulated structure. The bridging dppbz appears as a singlet in the ${ }^{31} \mathrm{P}$ NMR spectrum at $\delta 6.41$. The different aromatic hydrogens, associated with the four phenyl groups $(\mathrm{Ph})$ and the benzo group, could not be assigned with certainty due to extensive overlap.

The thermal ellipsoid plot of the molecular structure of $\mathbf{2}$, as the $\mathrm{CH}_{2} \mathrm{Cl}_{2}$ solvate, shown in Figure 1 confirms the bridging disposition of the dppbz ligand, which spans the Os(1)-Os(2) vector. The Os-Os bond distances range from $2.8507(1) \AA(\mathrm{Os}(1)-\mathrm{Os}(2))$ to $2.8821(1) \AA(\mathrm{Os}(2)-\mathrm{Os}(3))$, and the $\mathrm{Os}(1)-\mathrm{P}(1)$ and $\mathrm{Os}(2)-\mathrm{P}(2)$ bond distances of $2.3359(6)$ and 2.3289(6) $\AA$ are slightly longer than those distances reported by us for $1,2-\mathrm{Os}_{3}(\mathrm{CO})_{10}(\mathrm{dppen})$ but are well within the accepted range observed in a variety of

(40) Phosphine ligand substitution in $1,2-\mathrm{Os}_{3}(\mathrm{CO})_{10}(\mathrm{MeCN})_{2}$ has been previously shown by Poë to proceed through a dissociative loss of the $\mathrm{MeCN}$ ligands. In the present case, capture of the initial unsaturated cluster, $\mathrm{Os}_{3}(\mathrm{CO})_{10}(\mathrm{MeCN})$, by the dppbz is predicted to afford $\mathrm{Os}_{3}(\mathrm{CO})_{10}(\mathrm{MeCN})\left(\eta^{1}\right.$-dppbz) with a pendant phosphine ligand. Rapid ring closure to generate $\mathbf{2}$ is the anticipated result from either $\mathrm{MeCN}$ dissociation or an associative interchange process where $\mathrm{MeCN}$ serves as the leaving group. See: (a) Dahlinger, K.; Poë, A. J.; Sayal, P. K.; Sekhar, V. C. Dalton Trans. 1986, 2145. (b) Hudson, R. H. E.; Poë, A. J.; Sampson, C. N.; Siegel, A. Dalton Trans. 1989, 2235.

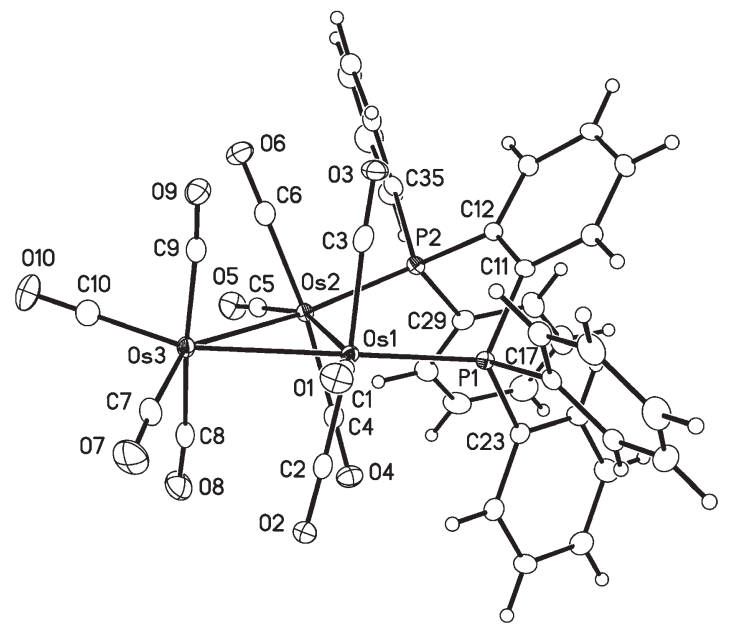

Figure 1. Thermal ellipsoid plot of $2 \cdot \mathrm{CH}_{2} \mathrm{Cl}_{2}$ at the $50 \%$ probability level with the hydrogen atoms shown as small spheres of arbitrary radii. The $\mathrm{CH}_{2} \mathrm{Cl}_{2}$ solvent has been omitted for clarity. Selected bond distances $(\AA)$ and angles (deg): Os(1)-P(1) = 2.3359(6), Os(1)-Os(2) = 2.8507(1), Os(1)-Os(2) = 2.8547(1), $\mathrm{Os}(2)-\mathrm{P}(2)=2.3289(6), \mathrm{Os}(2)-\mathrm{Os}(3)=2.8821(1), \mathrm{P}(1) \cdots \mathrm{P}-$ $(2)=3.6073(9) ; \mathrm{P}(1)-\mathrm{Os}(1)-\mathrm{Os}(3)=155.39(2), \mathrm{P}(2)-\mathrm{Os}(2)-$ $\mathrm{Os}(3)=156.27(2), \mathrm{C}(11)-\mathrm{P}(1)-\mathrm{Os}(1)=114.73(8), \mathrm{C}(12)-\mathrm{P}-$ $(2)-\mathrm{Os}(2)=120.62(8), \mathrm{C}(12)-\mathrm{C}(11)-\mathrm{P}(1)=125.3(2), \mathrm{C}(11)-$ $\mathrm{C}(12)-\mathrm{P}(2)=126.6(2)$.

phosphine-substituted polynuclear compounds. ${ }^{21 \mathrm{a}, 41}$ While the $\mathrm{P}(1)$ and $\mathrm{P}(2)$ atoms are equatorially disposed, they are tipped out of the plane defined by the three osmium atoms by $0.2765(6)$ and $-0.5657(6) \AA$, respectively. The $o$-phenylene platform that serves to tether the vicinal $\mathrm{Ph}_{2} \mathrm{P}$ moieties is defined by the atoms $\mathrm{C}(11)-\mathrm{C}(16)$, and this group is also tipped out of the metallic plane with a fold angle of $48.89(3)^{\circ}$. The ancillary carbonyl ligands are best viewed as linear groups, and the axial $\mathrm{CO}$ groups exhibit the commonly observed $D_{3}$ twist with respect to the metallic core. ${ }^{42}$

The bridging of the Os(1) and Os(2) atoms by the dppbz ligand in $\mathbf{2}$ is thermodynamically less favorable than the chelation in isomer $\mathbf{3}$. This factor also serves as the driving force for the facile isomerizations, observed in related, diphosphine-bridged isomers of $\mathrm{Os}_{3}(\mathrm{CO})_{10}(\mathrm{P}-\mathrm{P}) .^{21}$ Three significantly adverse perturbations result from the stretching of the dppbz ligand across the Os(1)-Os(2) vector in $\mathbf{2}$, and they in turn account for the ground-state destabilization in $\mathbf{2}$ relative to $\mathbf{3}$. The bridging dppbz ligand in $\mathbf{2}$ exhibits a

(41) Orpen, A. G.; Brammer, L.; Allen, F. K.; Kennard, O.; Watson, D. G.; Taylor, R. Dalton Trans. 1989, S1.

(42) (a) Alex, R. F.; Einstein, F. W. B.; Jones, R. H.; Pomeroy, R. K. Inorg. Chem. 1987, 26, 3175. (b) Bruce, M. I.; Liddell, M. J.; Skawkataly, O. B.; Hughes, C. A.; Skelton, B. H.; White, A. H. J. Organomet. Chem. 1988, 347, 207. 




Figure 2. Thermal ellipsoid plot of $\mathbf{3}$ at the $30 \%$ probability level with the hydrogen atoms shown as small spheres of arbitrary radii. Selected bond distances $(\AA)$ and angles $(\mathrm{deg})$ : Os(1) $-\mathrm{P}(2)=2.290(1), \operatorname{Os}(1)-\mathrm{P}(1)=2.294(1), \operatorname{Os}(1)-\mathrm{Os}(2)=$ 2.9092(5), Os(1)-Os(3) = 2.9263(5), Os(2)-Os(3) = 2.9109(4), $\mathrm{P}(1) \cdots \mathrm{P}(2)=3.094(2) ; \mathrm{P}(2)-\mathrm{Os}(1)-\mathrm{P}(1)=84.90(4), \mathrm{P}(2)-$ Os$(1)-\mathrm{Os}(2)=168.58(3), \mathrm{P}(1)-\mathrm{Os}(1)-\mathrm{Os}(2)=164.46(3), \mathrm{C}-$ $(1)-\mathrm{P}(1)-\mathrm{Os}(1)=108.6(2), \mathrm{C}(2)-\mathrm{P}(2)-\mathrm{Os}(1)=108.6(2)$, $\mathrm{C}(2)-\mathrm{C}(1)-\mathrm{P}(1)=116.9(3), \mathrm{C}(1)-\mathrm{C}(2)-\mathrm{P}(2)=117.9(3)$.

$\mathrm{P}(1) \cdots \mathrm{P}(2)$ internuclear bond distance (3.6073(9) $\AA$ ) that is $>0.4 \AA$ longer than the $\mathrm{P}(1) \cdots \mathrm{P}(2)$ internuclear bond distance reported for the free dppbz ligand. ${ }^{43}$ The angular deviation from $\mathrm{sp}^{2}$ hybridization of the $o$-phenylene $\mathrm{C}(11)$ and $\mathrm{C}(12)$ carbons found in the $\mathrm{C}(12)-\mathrm{C}(11)-\mathrm{P}(1)$ $\left(125.3(2)^{\circ}\right)$ and $\mathrm{C}(11)-\mathrm{C}(12)-\mathrm{P}(2)\left(126.6(2)^{\circ}\right)$ linkages exceeds the accepted VSEPR angle of $120^{\circ}$ by $>5^{\circ}$. A similar deformation from the accepted $\mathrm{sp}^{3}$ hybridization bond angle of ca. $109^{\circ}$ is also evidenced in the angles of $114.73(8)$ and $120.62(8)^{\circ}$ for the $\mathrm{C}(11)-\mathrm{P}(1)-\mathrm{Os}(1)$ and $\mathrm{C}(12)-\mathrm{P}(2)-$ Os(2) linkages, respectively. The observed fold angle of $43.95(2)^{\circ}$ along the $\mathrm{P}(1) \cdots \mathrm{P}(2)$ hinge of the six-membered ring, defined by the $\mathrm{Os}_{2} \mathrm{P}_{2} \mathrm{C}_{2}$ atoms, underscores the nonplanar disposition that exists between the $o$-phenylene and $\mathrm{Os}_{3}$ rings in 2.

Heating the ternary mixture of $\mathbf{2 - 4}$ under $1 \mathrm{~atm}$ of $\mathrm{CO}$ at $333 \mathrm{~K}$ overnight afforded $\mathbf{3}$ as the sole observable product, as determined by ${ }^{1} \mathrm{H}$ and ${ }^{31} \mathrm{P}$ NMR spectroscopy. This transformation verifies that $\mathbf{3}$ is the thermodynamically most stable of the isomeric $\mathrm{Os}_{3}(\mathrm{CO})_{10}(\mathrm{dppbz})$ clusters. The addition of CO suppresses the formation of the hydride cluster 4 , but $\mathrm{CO}$ addition has been shown not to affect the equilibrium for the bridged-to-chelated ligand isomerization in other decacarbonyl clusters $\mathrm{Os}_{3}(\mathrm{CO})_{10}(\mathrm{P}-\mathrm{P})$. $^{21}$

Cluster $\mathbf{3}$ was isolated by column chromatography and characterized in solution by IR and NMR spectroscopy; the molecular structure was determined by X-ray diffraction analysis. The singlet recorded at $\delta 26.32$ in the ${ }^{31} \mathrm{P}$ NMR spectrum of $\mathbf{3}$ is in full agreement with a triosmium cluster possessing a chelating dppbz ligand. Figure 2 shows the thermal ellipsoid plot of the molecular structure of $\mathbf{3}$ and confirms the attendant isomerization of the dppbz ligand upon heating. The Os-Os bond distances range from

(43) Levason, W.; Reid, G.; Webster, M. Acta Crystallogr. 2006, C62, 440.
Table 3. Experimental Rate Constants for the Isomerization of $1,2-\mathrm{Os}_{3}(\mathrm{CO})_{10}(\mathrm{dppbz})$ to $1,1-\mathrm{Os}_{3}(\mathrm{CO})_{10}(\mathrm{dppbz})$ under $\mathrm{CO}^{a}$

\begin{tabular}{ccl}
\hline entry & temp $(\mathrm{K})$ & $10^{4} k\left(\mathrm{~s}^{-1}\right)$ \\
\hline 1 & 318.0 & $0.29(8)$ \\
2 & 323.0 & $0.50(7)$ \\
3 & 323.0 & $0.45(10)^{b}$ \\
4 & 323.0 & $0.58(9)^{c}$ \\
5 & 323.0 & $0.49(8)^{d}$ \\
6 & 328.0 & $1.01(12)$ \\
7 & 333.0 & $1.41(10)$ \\
8 & 338.0 & $2.63(16)$ \\
9 & 343.0 & $3.66(14)$
\end{tabular}

${ }^{a}$ The UV-vis kinetic data were collected in toluene using a ca. $10^{-4}$ $M$ solution of starting cluster by following the increase in the absorbance of the $365 \mathrm{~nm}$ band. Unless otherwise noted, all reactions were performed under $1 \mathrm{~atm}$ of $\mathrm{CO} .{ }^{b}$ Reaction carried out in an autoclave under $6.8 \mathrm{~atm}$ of CO. ${ }^{c}$ Reaction carried out in an autoclave under $34 \mathrm{~atm}$ of CO. ${ }^{d}$ Reaction carried out under argon in the presence of 10 equiv of $\mathrm{PPh}_{3}$.

2.9092(5) $\AA(\mathrm{Os}(1)-\mathrm{Os}(2))$ to $2.9263(5) \AA(\mathrm{Os}(1)-\mathrm{Os}(3))$. The internuclear $\mathrm{P}(1) \cdots \mathrm{P}(2)$ distance of $3.094(2) \AA$ has undergone a significant contraction, relative to that distance found in 2, and the angles associated with the Os(1)-P(1) $-\mathrm{C}(1)\left(108.6(2)^{\circ}\right), \mathrm{Os}(1)-\mathrm{P}(2)-\mathrm{C}(2)\left(108.6(2)^{\circ}\right), \mathrm{C}(2)-$ $\mathrm{C}(1)-\mathrm{P}(1)\left(116.9(3)^{\circ}\right)$, and $\mathrm{C}(1)-\mathrm{C}(2)-\mathrm{P}(2)\left(117.9(3)^{\circ}\right)$ linkages display values that are in excellent agreement with the idealized hybridization state of the subtended atom. The observed angle of $84.90(4)^{\circ}$ for the $\mathrm{P}(1)-\mathrm{Os}(1)-\mathrm{P}(2)$ atoms is in keeping with the chelating nature of the ancillary dppbz ligand and the bite angle reported in the three known dppbzchelated clusters $\operatorname{Ir}_{4}(\mathrm{CO})_{10}(\mathrm{dppbz}),{ }^{44} \mathrm{H}_{4} \mathrm{Ru}_{4}(\mathrm{CO})_{10}(\mathrm{dppbz}){ }^{45}$ and $\mathrm{HRu}_{6}\left(\mu_{5}-\mathrm{C}\right)\left(\mu_{3}-\mathrm{P}\right)(\mathrm{CO})_{14}(\mathrm{dppbz}){ }^{46}$ The remaining bond distances and angles are unremarkable and require no comment.

Our interest in the coordinative flexibility of diphosphine ligands in polynuclear clusters ${ }^{21,22}$ led us to measure the kinetics for the conversion $\mathbf{2} \rightarrow \mathbf{3}$. The isomerization reactions were conveniently monitored by UV-vis spectroscopy, under $\mathrm{CO}$, over the temperature range $318-343 \mathrm{~K}$; the firstorder rate constants given in Table 3 were obtained. The progress of each reaction was monitored by following the absorbance increase in the $365 \mathrm{~nm}$ band belonging to 3 . Figure 3 shows the spectral changes in the transformation 2 $\rightarrow 3$. The two clearly defined isosbestic points at 397 and 420 $\mathrm{nm}$ indicate that the isomerization is well-behaved and is free of kinetic complications. The absorbance versus time plot, depicted in the inset of Figure 3, shows the high quality of the least-squares fit of the $365 \mathrm{~nm}$ absorbance data to the growth of 3 by a first-order reaction. The effect of $\mathrm{CO}$ pressure (entries 2-4 in Table 3) and $\mathrm{PPh}_{3}$ (entry 5) on the reaction was also explored, and no significant changes in the rate constant were observed, relative to the standard value reported for entry 2 . The insensitivity of the rate constants to ligand additives and the Eyring activation parameters $\left(\Delta H^{\ddagger}\right.$ $\left.=21.6(3) \mathrm{kcal} / \mathrm{mol} ; \Delta S^{\ddagger}=-11(1) \mathrm{eu}\right)$ both strongly support an intramolecular isomerization scenario that involves the migration of phosphine and $\mathrm{CO}$ groups about the cluster polyhedron. The details of these migrations were

(44) Park, B. K.; Miah, M. A.; Kang, H.; Lee, K.; Cho, Y.-J.; Churchill, D. G.; Park, S.; Choi, M.-G.; Park, J. T. Organometallics 2005, 24, 675 .

(45) Nesterov, V. N.; Watson, W. H.; Kandala, S.; Richmond, M. G. Polyhedron 2007, 26, 3602 .

(46) Watson, W. H.; Kandala, S.; Richmond, M. G. J. Organomet. Chem. 2007, 692, 1648 . 


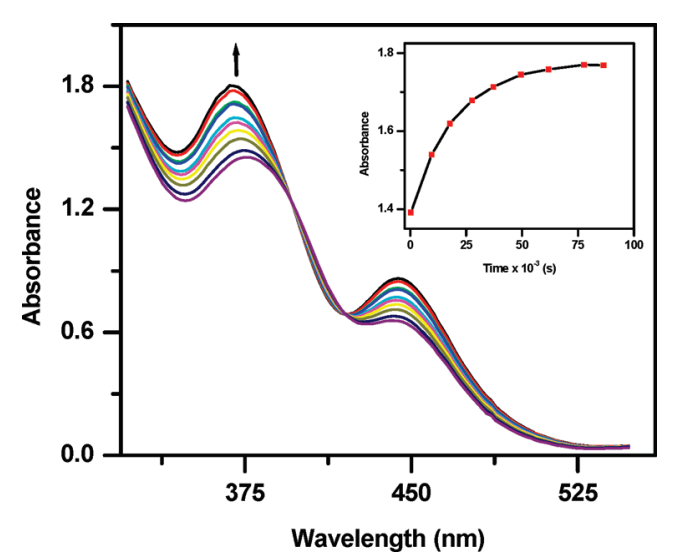

Figure 3. Representative UV-vis spectral changes for the isomerization $\mathbf{2} \rightarrow \mathbf{3}$ in toluene at $323 \mathrm{~K}$ under $1 \mathrm{~atm}$ of $\mathrm{CO}$. The inset shows the absorbance versus time plot for the experimental data ( $\square$ ) and the nonlinear regression fit of the first-order rate constant $k$ (solid black line).

investigated by the DFT calculations, the results of which are described in a subsequent section.

II. Reversible Ortho Metalation in 3 and Formation of $\mathrm{HOs}_{3}(\mathrm{CO})_{9}\left[\mu-1,2-\mathrm{PhP}\left(\mathrm{C}_{6} \mathrm{H}_{4}-\eta^{1}\right) \mathbf{C}_{6} \mathbf{H}_{4} \mathbf{P P h}_{2}\right]$ (4). As part of our ongoing studies of bond-activation processes, involving cluster-coordinated bidentate ligands, ${ }^{20-22,42,47-49}$ the origin and structural composition of the hydride cluster 4 that was isolated from the reaction between $\mathbf{1}$ and dppbz were next examined. While cluster $\mathbf{3}$ is thermally stable to CO loss at temperatures below $353 \mathrm{~K}$, it is very sensitive to near-UV irradiation. Photolysis of a toluene solution containing $\mathbf{3}$, using $366 \mathrm{~nm}$ light, led to $\mathrm{CO}$ loss and formation of 4 . The hydride-bridged cluster 4 could be obtained in quantitative yield, provided that the liberated $\mathrm{CO}$ was periodically removed through freeze-pump-thaw degas cycles or by active argon purge during irradiation.

In terms of the mechanism of formation of $\mathbf{4}$ from photolysis of $\mathbf{3}$, optical excitation within the $\sigma \rightarrow \sigma^{*}$ manifold is expected to promote the formation of the putative, unsaturated cluster $\mathrm{Os}_{3}(\mathrm{CO})_{9}(\mathrm{dppbz})$ through loss of one $\mathrm{CO}$. This latter cluster is extremely sensitive to the presence of the released $\mathrm{CO}$, which must be removed to avoid the regeneration of cluster $\mathbf{3}$. Treatment of an isolated sample of $\mathbf{4}$ with $\mathrm{CO}$ (1 atm) overnight at $333 \mathrm{~K}$ in toluene led to the quantitative formation of $\mathbf{3}$, thus establishing the reversible nature of the ortho metalation of the ancillary dppbz ligand. This reactivity paradigm appears to be general, in that several other activated diphosphine ligands have been shown by us to regenerate their respective $\mathrm{Os}_{3}(\mathrm{CO})_{10}(\mathrm{P}-\mathrm{P})$ cluster upon carbonylation. ${ }^{21,49}$

4 was isolated in $88 \%$ yield after purification by column chromatography over alumina, followed by recrystallization. The presence of a bridging hydride at $\delta-16.43$ in the ${ }^{1} \mathrm{H}$ NMR spectrum and the pair of inequivalent doublets at $\delta$ 28.62 and 39.54 in the ${ }^{31} \mathrm{P}$ NMR spectrum are in keeping with the formulated structure of $\mathbf{4}$. Figure 4 shows the thermal ellipsoid plot of the molecular structure of $\mathbf{4}$, as the $\mathrm{CH}_{2} \mathrm{Cl}_{2}$

(47) Poola, B.; Carrano, C. J.; Richmond, M. G. Organometallics 2008, 27, 3018 .

(48) Kandala, S.; Hammons, C.; Watson, W. H.; Wang, X.; Richmond, M. G. Dalton Trans. 2010, 39, 1620.

(49) Huang, S.-H.; Keith, J. M.; Hall, M. B.; Richmond, M. G. Organometallics 2010, 29, 4041.



Figure 4. Thermal ellipsoid plot of $\mathbf{4} \cdot \mathrm{CH}_{2} \mathrm{Cl}_{2}$ at the $50 \%$ probability level with the hydrogen atoms shown as small spheres of arbitrary radii. The $\mathrm{CH}_{2} \mathrm{Cl}_{2}$ solvent has been omitted for clarity. Selected bond distances $(\AA)$ and angles (deg): Os(1)-Os(3) = 2.8808(4), Os(1)-Os(2) = 2.9330(3), Os(2)-P(2) = 2.323(1), $\mathrm{Os}(2)-\mathrm{P}(1)=2.367(2), \mathrm{Os}(2)-\mathrm{Os}(3)=2.9948(4), \mathrm{Os}(3)-\mathrm{C}(11)=$ 2.184(6), $\mathrm{P}(1) \cdots \mathrm{P}(2)=3.076(2) ; \mathrm{P}(2)-\mathrm{Os}(2)-\mathrm{P}(1)=81.94(5)$, $\mathrm{P}(2)-\mathrm{Os}(2)-\mathrm{Os}(1)=172.92(4), \mathrm{P}(1)-\mathrm{Os}(2)-\mathrm{Os}(1)=97.55(4)$, $\mathrm{C}(16)-\mathrm{P}(1)-\mathrm{Os}(2)=106.7(2), \mathrm{C}(17)-\mathrm{P}(2)-\mathrm{Os}(2)=109.4(2)$, $\mathrm{C}(17)-\mathrm{C}(16)-\mathrm{P}(1)=118.1(4), \mathrm{C}(16)-\mathrm{C}(17)-\mathrm{P}(2)=116.2(4)$.

solvate, and confirms the ortho metalation of one of the aryl rings of the dppbz ligand. 4 contains $48 \mathrm{e}$ and is electronically saturated, assuming that the ancillary $\mathrm{PhP}\left(\mathrm{C}_{6} \mathrm{H}_{4}\right.$ $\left.\eta^{1}\right) \mathrm{C}_{6} \mathrm{H}_{4} \mathrm{PPh}_{2}$ ligand functions as a 5e-donor group. The Os-Os bond lengths range from 2.8808(4) $\AA$ (Os(1)Os(3)) to 2.9948(4) $\AA$ (Os(2)-Os(3)) and reveal a mean distance of $2.9362 \AA$ that parallels those Os-Os bond distances reported for other $\mathrm{Os}_{3}$ clusters. Both phosphine atoms are coordinated to the Os(2) center and display axial $(\mathrm{P}(1))$ and equatorial $(\mathrm{P}(2))$ dispositions. The bridging hydride was not located during structural refinement, but it may be confidently assigned to the Os(2)-Os(3) bond, on the basis of the elongated distance of this bond, relative to the other two Os-Os bonds, and the stereochemical disposition of the $\mathrm{C}(9) \mathrm{O}(9)$ and $\mathrm{P}(2)$ groups about the cluster polyhedron. ${ }^{50}$ Here the $\mathrm{Os}(2)-\mathrm{Os}(3)-\mathrm{C}(9)$ and Os(3)-Os(2) $-\mathrm{P}(2)$ angles of $117.6(2)$ and $114.87(3)^{\circ}$, respectively, are significantly expanded from the idealized value of ca. $90^{\circ}$ typically found for equatorial substituents in triangular clusters, due to the presence of the ancillary hydride. ${ }^{51}$ The Os(3) $-\mathrm{C}(11)$ bond distance of 2.184(6) $\AA$ is comparable to the $\mathrm{Os}-\mathrm{C}$ bond distance found in the triosmium clusters $\mathrm{H}_{2} \mathrm{Os}_{3}(\mathrm{CO})_{9}\left(\mu-\mathrm{C}_{6} \mathrm{H}_{4} \mathrm{PPh}\right), \quad \mathrm{HOs}_{3}(\mathrm{CO})_{9}\left(\mathrm{PPh}_{3}\right)\left(\mu-\mathrm{SbPh}_{2}\right)(\mu-$ $\left.\mathrm{C}_{6} \mathrm{H}_{4}\right)$, and $\mathrm{Os}_{3}(\mathrm{CO})_{9}\left[\mu-\mathrm{PPh}\left(\mathrm{C}_{6} \mathrm{H}_{4}\right) \mathrm{CH}_{2} \mathrm{PPh}\right]$, each of which possess an activated aryl moiety. ${ }^{52}$

(50) (a) Mingos, D. M. P.; Wales, D. J. Introduction to Cluster Chemistry; Prentice Hall: Englewood Cliffs, NJ, 1990. (b) Teller, R. G.; Bau, R. Struct. Bonding (Berlin) 1981, 41, 1.

(51) (a) Churchill, M. R.; Hollander, F. J.; Lashewycz, R. A.; Pearson, G. A.; Shapley, J. R. J. Am. Chem. Soc. 1981, 103, 2430. (b) Churchill, M. R.; Hollander, F. J. Inorg. Chem. 1981, 20, 4124.

(52) (a) Colbran, S. B.; Irele, P. T.; Johnson, B. F. G.; Lahoz, F. J.; Lewis, J.; Raithby, P. R. Dalton Trans. 1989, 2023. (b) Chen, G.; Deng, M.; Lee, C. K.; Leong, W. K. Organometallics 2002, 21, 1227. (c) Kabir, S. E.; Miah, M. A.; Sarker, N. C.; Hussain, G. M. G.; Hardcastle, K. I.; Nordlander, E.; Rosenberg, E. Organometallics 2005, 24, 3315. 




$\mathrm{H}_{2} \mathrm{Os}_{3}(\mathrm{CO})_{8}\left[\mu-\mathrm{Ph}_{2} \mathrm{P}\left(\mathrm{CH}_{2}\right)_{3} \mathrm{P}\left(\mathrm{C}_{6} \mathrm{H}_{4}-\eta{ }^{1}\right)\right]$

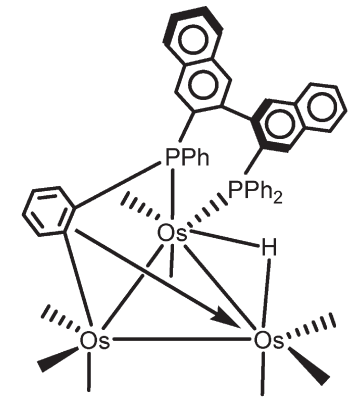

$\mathrm{HOS}_{3}(\mathrm{CO})_{8}\left[\mu-(\mathrm{R})-\mathrm{BINAP}\left(\eta^{1}, \pi\right)-\mathrm{H}\right]$
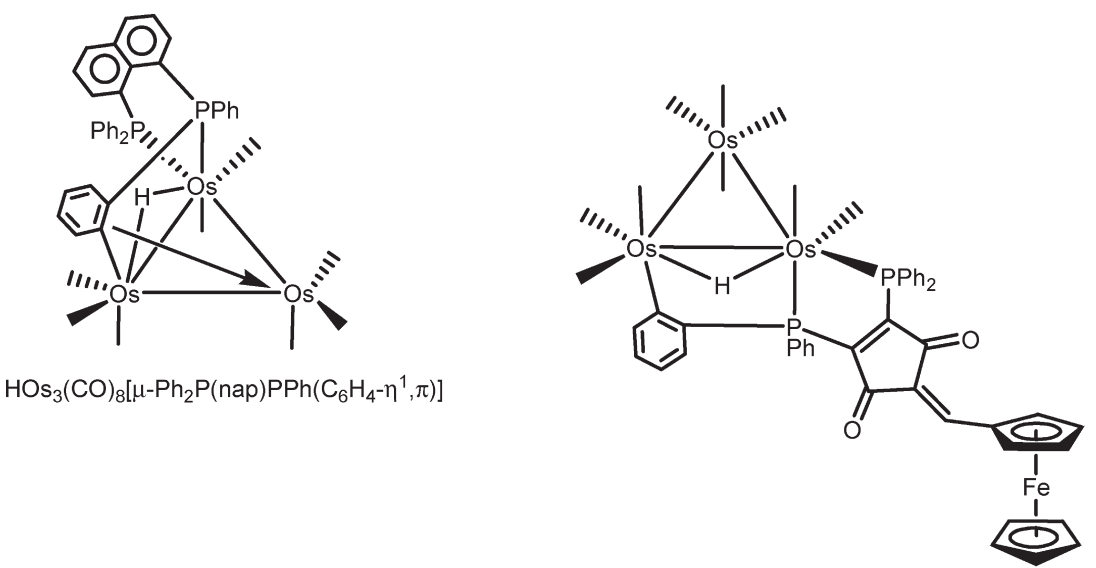

$\mathrm{HOs}_{3}(\mathrm{CO})_{9}\left[\mu-\mathrm{PhP}\left(\mathrm{C}_{6} \mathrm{H}_{4}-\eta^{1}\right) \mathrm{C}=\mathrm{C}\left(\mathrm{PPh}_{2}\right) \mathrm{C}(\mathrm{O}) \mathrm{C}=\mathrm{CH}\left(\mathrm{C}_{5} \mathrm{H}_{4} \mathrm{FeCp}\right) \mathrm{C}(\mathrm{O})\right]$

Decarbonylation of other $1,1-\mathrm{Os}_{3}(\mathrm{CO})_{10}(\mathrm{P}-\mathrm{P})$ clusters, followed by ortho metalation of the diphosphine ligand, is observed upon heating; however, the composition of the resulting product is highly dependent upon the nature of the initial diphosphine, and further activation of the metalated aryl group is often found under harsh reaction conditions (i. e., refluxing toluene or heptane). A check of the Cambridge Structural Database (CSD version 5.31) for $\mathrm{Os}_{3}$ clusters, possessing a chelating diphosphine that has experienced ortho metalation, reveals only four structures on file. Scheme 2 shows these four clusters, whose structural diversity is immediately obvious. Thermolysis of $1,1-\mathrm{Os}_{3}(\mathrm{CO})_{10}(\mathrm{dppp})$ in toluene under $\mathrm{H}_{2}$ leads to the elimination of benzene and formation of the phosphido-bridged cluster $\mathrm{H}_{2} \mathrm{Os}_{3}(\mathrm{CO})_{8}[\mu$ $\left.\mathrm{Ph}_{2} \mathrm{P}\left(\mathrm{CH}_{2}\right)_{3} \mathrm{P}\left(\mathrm{C}_{6} \mathrm{H}_{4}-\eta^{1}\right)\right] .{ }^{53}$ Heating the corresponding $(R)$ BINAP and dppn decacarbonyl derivatives gives rise to the ortho-metalated products $\mathrm{HO}_{3}(\mathrm{CO})_{8}\left[\mu-(R)-\operatorname{BINAP}\left(\eta^{1}, \pi\right)\right.$ $\mathrm{H}]$ and $\mathrm{HOs}_{3}(\mathrm{CO})_{8}\left[\mu-\mathrm{Ph}_{2} \mathrm{P}(\right.$ nap $\left.) \mathrm{PPh}\left(\mathrm{C}_{6} \mathrm{H}_{4}-\eta^{1}, \pi\right)\right]$, where the activated aryl ring in each product functions as a $7 \mathrm{e}$ facecapping donor ligand. ${ }^{54,55}$ Only $\mathrm{HOs}_{3}(\mathrm{CO})_{9}[\mu-\mathrm{PhP}-$ $\left.\left(\mathrm{C}_{6} \mathrm{H}_{4}\right) \mathrm{C}=\mathrm{C}\left(\mathrm{PPh}_{2}\right) \mathrm{C}(\mathrm{O}) \mathrm{C}=\mathrm{CH}\left(\mathrm{C}_{5} \mathrm{H}_{4} \mathrm{FeCp}\right) \mathrm{C}(\mathrm{O})\right]$, which was obtained as a ca. 1:1 mixture of diastereomers from the photolysis of $1,1-\mathrm{Os}_{3}(\mathrm{CO})_{10}(\mathrm{fbpcd})$ (where fbpcd $=2$-(ferrocenylidene)-4,5-bis(diphenylphosphino)-4-cyclopenten-1,3-dione), exhibits a structure that is similar to that of $4 .^{21 \mathrm{~d}}$

(53) Deeming, A. J.; Hardcastle, K. I.; Kabir, S. E. Dalton Trans. 1988, 827 .

(54) Deeming, A. J.; Stchedroff, M. Dalton Trans. 1998, 3819

(55) Bruce, M. I.; Humphrey, P. A.; Schmutzler, R.; Skelton, B. W.; White, A. J. Organomet. Chem. 2004, 689, 2415.
III. Diphosphine Chelation in the Reaction of $1,2-\mathrm{Os}_{3}$ $(\mathrm{CO})_{10}(\mathrm{MeCN})_{2}$ with $\mathbf{d p p b z F}_{4}$. Treatment of $\mathbf{1}$ with a measured excess of $\mathrm{dppbzF}_{4}$ at room temperature furnished 1,1$\mathrm{Os}_{3}(\mathrm{CO})_{10}\left(\mathrm{dppbzF}_{4}\right)(\mathbf{6})$ as the sole observable product, as assessed by ${ }^{31} \mathrm{P}$ NMR spectroscopy. Repeating the reaction at $0{ }^{\circ} \mathrm{C}$ in a sealed NMR tube afforded the same product, albeit more slowly. The inability to observe $1,2-\mathrm{Os}_{3}(\mathrm{CO})_{10^{-}}$ $\left(\mathrm{dppbzF}_{4}\right)(5)$ spectroscopically indicates that the expected kinetic substitution product is unstable. Presumably, this instability is due to unfavorable steric interactions between the $\mathrm{Ph}_{2} \mathrm{P}$ moieties and the ortho fluorines, interactions that are exacerbated by the coordination of the diphosphine ligand across the Os-Os bond. ${ }^{56}$ The rapid isomerization of 5 to the thermodynamically more stable, diphosphinechelated cluster $\mathbf{6}$ alleviates the strain in the "stretched" $\mathrm{dppbzF}_{4}$ ligand. Scheme 3 summarizes the results of the reaction between $\mathbf{1}$ and $\mathrm{dppbzF}_{4}$.

6 was isolated in $85 \%$ yield after column chromatography over silica gel, followed by recrystallization, and it was characterized by IR and NMR spectroscopy, combustion analysis, and X-ray crystallography. The ${ }^{31} \mathrm{P}$ NMR spectrum revealed a diagnostic singlet at $\delta 34.00$, while the ${ }^{1} \mathrm{H}$ NMR spectrum displayed three aromatic resonances at $\delta 7.20,7.34$, and 7.76 in a 4:8:8 integral ratio for the para, meta, and ortho hydrogens, belonging to the two $\mathrm{PPh}_{2}$ moieties. The structure of $6^{1} / 2$ (benzene) is shown in Figure 5, where the

(56) For manifestations of the buttressing effect in chemical syntheses and the thermochemical properties of alkyl-substituted phenols, see: (a) Sammes, P. G.; Weller, D. J. Synthesis 1995, 1205. (b) Choony, N.; Dadabhoy, A.; Sammes, P. G. J. Chem. Soc., Perkin Trans. 1 1998, 2017. (c) Verevkin, S. P. J. Chem. Thermodyn. 1999, 31, 1397. 


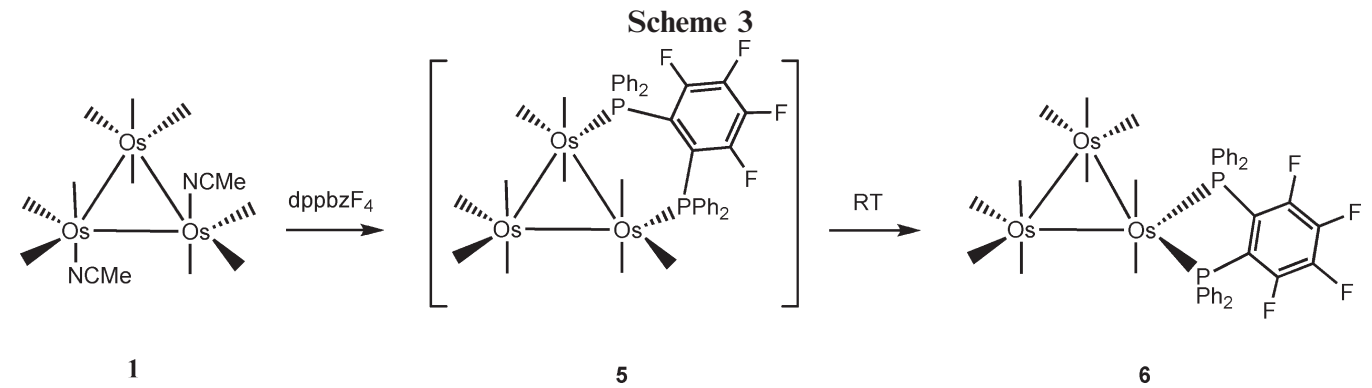



Figure 5. Thermal ellipsoid plot of one of the two independent molecules of $\mathbf{6}^{1}{ }_{2} \mathrm{C}_{6} \mathrm{H}_{6}$ at the $50 \%$ probability level. The hydrogen atoms are shown as small spheres of arbitrary radii, and the $\mathrm{C}_{6} \mathrm{H}_{6}$ solvent has been omitted for clarity. Selected bond distances $(\AA)$ and angles $(\mathrm{deg})$ : Os(1) $-\mathrm{P}(2)=2.276(2)$, Os$(1)-\mathrm{P}(1)=2.290(1), \mathrm{Os}(1)-\mathrm{Os}(2)=2.8871(3), \mathrm{Os}(1)-\mathrm{Os}(3)=$ 2.9093(3), Os(2)-Os(3) = 2.8948(4), P(1) $\cdots \mathrm{P}(2)=3.106(2)$; $\mathrm{P}(2)-\mathrm{Os}(1)-\mathrm{P}(1)=85.74(5), \mathrm{P}(2)-\mathrm{Os}(1)-\mathrm{Os}(2)=165.99(4)$, $\mathrm{P}(1)-\mathrm{Os}(1)-\mathrm{Os}(3)=167.75(3), \mathrm{C}(11)-\mathrm{P}(1)-\mathrm{Os}(1)=107(1)$, $\mathrm{C}(12)-\mathrm{P}(2)-\mathrm{Os}(1)=107.2(2), \mathrm{C}(12)-\mathrm{C}(11)-\mathrm{P}(1)=116.9(4)$, $\mathrm{C}(11)-\mathrm{C}(12)-\mathrm{P}(2)=117.6(4)$.

presence of a chelating $\mathrm{dppbzF}_{4}$ ligand is verified. The two independent molecules of $\mathbf{6}$ found in the unit cell do not exhibit any significant differences in geometries, and to our knowledge, the present example represents the first structurally characterized organometallic compound that contains the dppbzF 4 ligand. ${ }^{57}$ The mean Os-Os bond distance in $\mathbf{6}$ is $2.8971 \AA$ and is slightly shorter than the mean distance found for the Os-Os bonds in 3. The ancillary aryl groups associated with the $\mathrm{P}(2)$ and $\mathrm{P}(3)$ atoms in the molecules of 6 are disordered over two positions. The observed bite angles for the chelating dppzF 4 ligands in the two independent molecules found in the crystal structure are $85.74(5)$ and $86.81(6)^{\circ}$ for the $\mathrm{P}(1)-\mathrm{Os}(1)-\mathrm{P}(2)$ and $\mathrm{P}(3)-\mathrm{Os}(4)-\mathrm{P}(4)$ linkages and are similar to the $84.90(4)^{\circ}$ bite angle observed in $\mathbf{3}$ for the dppbz ligand.

IV. Synthesis and X-ray Diffraction Structure of $\mathrm{HOs}_{3}$ (CO) $)_{9}\left[\boldsymbol{\mu}-\mathbf{1 , 2}-\mathbf{P h P}\left(\mathbf{C}_{6} \mathbf{H}_{\mathbf{4}}-\boldsymbol{\eta}^{\mathbf{1}}\right) \mathbf{C}_{\mathbf{6}} \mathbf{F}_{\mathbf{4}} \mathbf{P P h}_{\mathbf{2}}\right]$. The thermal and

(57) For a report on an iron complex containing the related ligand 1,2-bis(dimethylphosphino)tetrafluorobenzene, see: Higgins, S. J.; Jewiss, H. C.; Levason, W.; Webster, M. Acta Crystallogr. 1985, C41, 695.

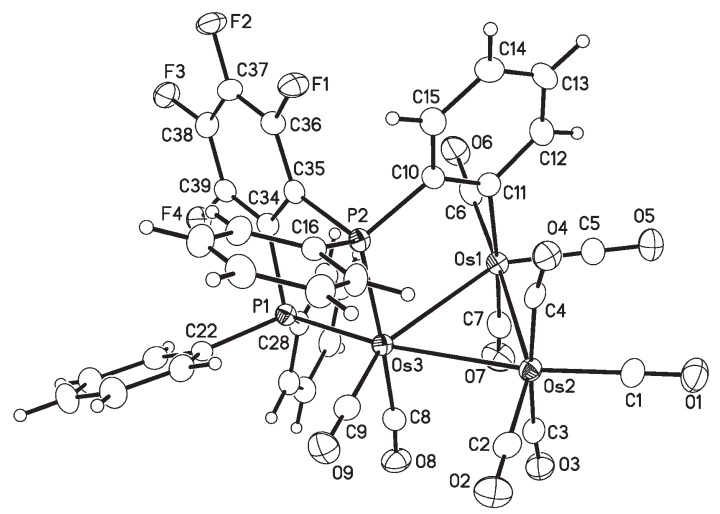

Figure 6. Thermal ellipsoid plot of $7 \cdot \mathrm{CHCl}_{3}$ at the $50 \%$ probability level, with the carbon and hydrogen atoms shown as small spheres of arbitrary radii. The $\mathrm{CHCl}_{3}$ solvent has been omitted for clarity. Selected bond distances (A) and angles (deg): $\mathrm{Os}(1)-\mathrm{C}(11)=2.186(4), \mathrm{Os}(1)-\mathrm{Os}(2)=2.8714(3), \mathrm{Os}(1)-\mathrm{Os}-$ $(3)=2.9812(3), \operatorname{Os}(2)-\mathrm{Os}(3)=2.9399(3), \operatorname{Os}(3)-\mathrm{P}(1)=$ $2.307(1), \mathrm{Os}(3)-\mathrm{P}(2)=2.366(1), \mathrm{P}(1) \cdots \mathrm{P}(2)=3.139(2)$; $\mathrm{P}-$ $(1)-\mathrm{Os}(3)-\mathrm{P}(2)=84.41(4), \mathrm{P}(1)-\mathrm{Os}(3)-\mathrm{Os}(2)=165.45(3)$, $\mathrm{P}(2)-\mathrm{Os}(3)-\mathrm{Os}(2)=98.38(3), \mathrm{C}(34)-\mathrm{P}(1)-\mathrm{Os}(3)=108.6(1)$, $\mathrm{C}(35)-\mathrm{P}(2)-\mathrm{Os}(3)=106.4(1), \mathrm{C}(35)-\mathrm{C}(34)-\mathrm{P}(1)=117.1(3)$, $\mathrm{C}(34)-\mathrm{C}(35)-\mathrm{P}(2)=118.8(3)$.

photochemical properties of $\mathbf{6}$ were explored, in order to check whether there are any reactivity differences between it and 3.6 is stable to $\mathrm{CO}$ loss at $333 \mathrm{~K}$ but reacts in a manner identical with that of $\mathbf{3}$ under photolysis conditions $(366 \mathrm{~nm})$, to afford the corresponding hydride-bridged cluster 7 . Treatment of 7 with excess $\mathrm{CO}$ at $333 \mathrm{~K}$ regenerates $\mathbf{6}$ in quantitative yield. The ortho metalation of the ancillary diphosphine ligand occurs without complications, and the spectroscopic properties for 7 are consistent with the proposed structure

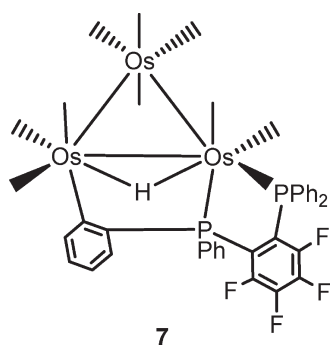

Figure 6 shows the thermal ellipsoid plot of $7 \cdot \mathrm{CHCl}_{3}$, whose overall molecular architecture is compositionally similar to that of 4 . The Os-Os bond distances vary from 2.8714(3) $\AA(\mathrm{Os}(1)-\mathrm{Os}(2))$ to $2.9812(3) \AA(\mathrm{Os}(1)-\mathrm{Os}(3))$, with the latter bond presumably serving as the locus for the bridging hydride that was not found during data reduction and refinement. The $\mathrm{Os}(1)-\mathrm{C}(11)$ bond distance of 2.186(4) 


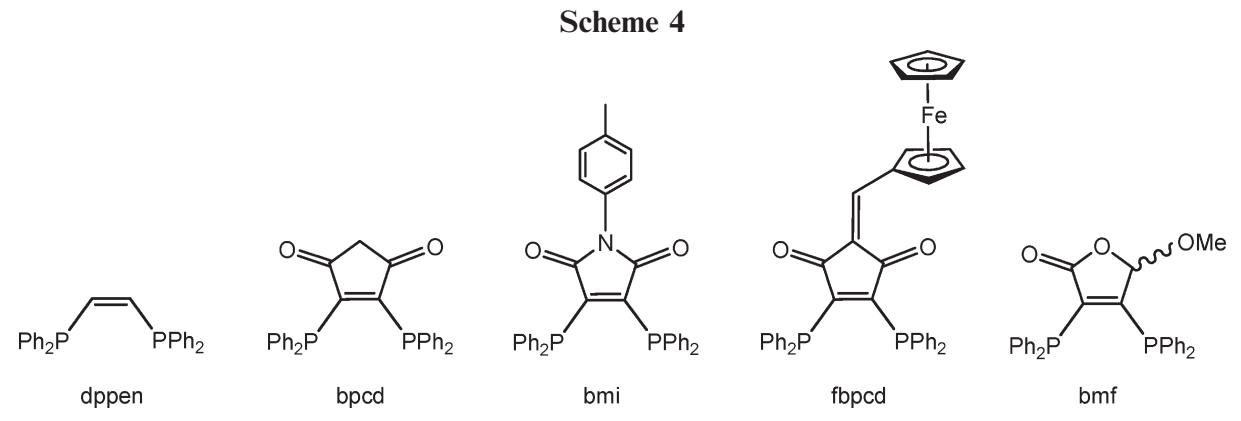

Table 4. Eyring Activation Data for the Isomerization of 1,2$\mathrm{Os}_{3}(\mathrm{CO})_{10}(\mathrm{P}-\mathrm{P})$ to $1,1-\mathrm{Os}_{3}(\mathrm{CO})_{10}(\mathrm{P}-\mathrm{P})$

\begin{tabular}{lccl}
\hline ligand & $\Delta H^{\ddagger}(\mathrm{kcal} / \mathrm{mol})$ & $\Delta S^{\ddagger}(\mathrm{eu})$ & \multicolumn{1}{c}{ ref } \\
\hline dppen $^{a}$ & $26.5(6)$ & $-5(2)$ & $21 \mathrm{a}$ \\
bpcd & $25.0(7)$ & $-2(2)$ & $21 \mathrm{~b}$ \\
bmi & $24.0(1)$ & $-5(1)$ & $21 \mathrm{c}$ \\
fbpcd & $23.1(3)$ & $-7(1)$ & $21 \mathrm{~d}$ \\
dppbz & $21.6(3)$ & $-11(1)$ & this work \\
bmf $^{a}$ & $26.9(7)$ & $6(1)$ & unpublished
\end{tabular}

${ }^{a}$ The isomerization is reversible, and only the activation parameters for the forward portion of the reaction are reported.

$\AA$ compares favorably to the corresponding Os-C bond distance found in $\mathbf{4}$. The remaining bond distances and angles are unremarkable with respect to $\mathbf{4}$ and related osmium clusters characterized by our groups.

V. Possible Mechanisms for Diphosphine Isomerization in $\mathbf{O s}_{\mathbf{3}}(\mathbf{C O})_{\mathbf{1 0}}(\mathbf{P}-\mathbf{P})$. The kinetics and activation parameters for the conversion $\mathbf{2} \rightarrow \mathbf{3}$ are in keeping with those found in related $\mathrm{Os}_{3}(\mathrm{CO})_{10}(\mathrm{P}-\mathrm{P})$ clusters. Scheme 4 shows the different bidentate diphosphine ligands that have been examined and that undergo bridging to chelating isomerization in $\mathrm{Os}_{3}(\mathrm{CO})_{10}(\mathrm{P}-\mathrm{P})$ clusters. Table 4 summarizes the Eyring data for the different diphosphine-substituted clusters. The data reveal a high degree of uniformity and strongly support a common mechanism for the isomerization of these diphosphine ligands about the $\mathrm{Os}_{3}$ polyhedron, namely a nondissociative, first-order reaction, whose rate depends only on the $\mathrm{Os}_{3}(\mathrm{CO})_{10}(\mathrm{P}-\mathrm{P})$ cluster.

As already noted, the $\mathrm{dppbzF}_{4}$ ligand is atypical, inasmuch as the expected ligand-bridged cluster $\mathbf{5}$ was not observed when 1 was allowed to react with dppbzF 4 . Instead, only the chelated isomer 6 was observed. This finding suggests that the enthalpy of activation for the rearrangement of $\mathbf{5}$ to $\mathbf{6}$ is lower than the enthalpies of activation, given in Table 4, for the rearrangements of all of the other $\mathrm{Os}_{3^{-}}$ $(\mathrm{CO})_{10}(\mathrm{P}-\mathrm{P})$ clusters in the table. The data in Table 4 allow one to estimate that $\Delta H^{\ddagger}<20 \mathrm{kcal} / \mathrm{mol}$ for the rearrangement of 5 to $\mathbf{6}$.

The migration of $\mathrm{P}$ in the bridging-to-chelating transformation of the ancillary diphosphine ligand in $\mathrm{Os}_{3}(\mathrm{CO})_{10}(\mathrm{P}-$ $\mathrm{P})$ must be accompanied, at a minimum, by the permutation of at least one $\mathrm{CO}$ group between adjacent osmium centers. Two scenarios can account for the phenomenologically observed diphosphine isomerization in these molecules. The first scenario involves a pairwise exchange of a $\mathrm{CO}$ with

(58) In theory, these two isomerization mechanisms may be differentiated on the basis of the temperature-dependent behavior of the ancillary CO ligands in $1,2-\mathrm{Os}_{3}(\mathrm{CO})_{10}(\mathrm{P}-\mathrm{P})$. Unfortunately, global CO scrambling has been found to be competitive with the phosphine migration process, negating a mechanistic distinction by VT ${ }^{13} \mathrm{C}$ NMR spectroscopy. one of the phosphorus atoms across one of the Os-Os vectors. The second mechanism consists of a merry-goround migration of two $\mathrm{CO}$ groups and one of the phosphorus atoms about the equatorial plane of the cluster. ${ }^{58}$ Both mechanistic possibilities draw on established paradigms for $\mathrm{CO}$ fluxionality in polynuclear clusters, ${ }^{59}$ and each isomerization process requires the formation of a nonclassical, bridging phosphorus atom along the reaction coordinate, during the transit of phosphorus across an Os-Os bond. ${ }^{60}$

Entry into the pairwise exchange process mandates the presence of an axially disposed phosphine moiety, prior to the simultaneous migration of this phosphine and a trans axial $\mathrm{CO}$ group across a connecting Os-Os bond. The isomerization of a phosphine moiety from its initial equatorial site (e) in the bridged isomer (B) to an axial position (a) could be achieved by exchange between $\mathrm{Os}_{1}$ and $\mathrm{Os}_{3}$ of two axial CO groups, situated on opposite sides of the threemembered Os ring. ${ }^{61,62}$ The exchange mechanism requires conrotation of the other four substituents that lie

(59) For reports that deal with the elucidation of reaction mechanisms in polynuclear clusters using DFT calculations, see: (a) Persson, R.; Monari, M.; Gobetto, R.; Russo, A.; Aime, S.; Calhorda, M. J.; Nordlander, E. Organometallics 2001, 20, 4150. (b) Abdul Mottalib, M.; Begum, N.; Tareque Abedin, S. M.; Akter, T.; Kabir, S. E.; Arzu Miah, M.; Rokhsana, D.; Rosenberg, E.; Golzar Hossain, G. M.; Hardcastle, K. I. Organometallics 2005, 24, 4747. (c) Musaev, D. G.; NowrooziIsfahami, T.; Morokuma, K.; Rosenberg, E. Organometallics 2005, 24 , 5973. (d) Musaev, D. G.; Nowroozi-Isfahami, T.; Morokuma, K.; Abedin, J.; Rosenberg, E.; Hardcastle, K. I. Organometallics 2006, 25, 203. (e) Li, Q.-S.; Xu, B.; Xie, Y.; King, R. B.; Schaefer, H. F. Dalton Trans. 2007, 4312. (f) Cabeza, J. A.; Pérez-Carreño, E. Organometallics 2008, 27, 4697. (g) Cabeza, J. A.; del Río, I.; Fernández-Colinas, J. M.; Pérez-Carreño, E.; Sánchez-Vega, M. G.; Vázquez-García, D. Organometallics 2009, 28, 1832. (h) Cabeza, J. A.; Fernández-Colinas, J. F.; Pérez-Carreño, E. Organometallics 2009, 28, 4217. (i) Cabeza, J. A.; Van der Maelen, J. F.; García-Granda, S. Organometallics 2009, 28, 3666. (j) Cabeza, J. A.; del Río, I.; Goite, M. C.; Pérez-Carreño, E.; Pruneda, V. Chem. Eur. J. 2009, 15, 7339.

(60) A kinetically indistinguishable mechanism, involving the unsaturated cluster $\mathrm{Os}_{3}(\mathrm{CO})_{10}\left(\eta^{1}-\mathrm{P}-\mathrm{P}\right)$, formed through the dissociation of one arm of the diphosphine ligand from $1,2-\mathrm{Os}_{3}(\mathrm{CO})_{10}(\mathrm{P}-\mathrm{P})$, cannot be completely eliminated from consideration. However, given the rigid nature and syn disposition of the diphosphine ligands depicted in Scheme 4 and the uniformly negative entropies of activation in Table 4, this alternative does not seem likely.

(61) The isomerization of a phosphine moiety from an equatorial site to an axial site in the bridged isomer could, in principle, also be achieved by a $90^{\circ}$ trigonal twist of the four substiuents at one osmium center. However. in $\mathrm{Os}_{3}(\mathrm{CO})_{12}$, the activation barrier for the $90^{\circ}$ trigonal-twist pathway is computed to be $5.4 \mathrm{kcal} / \mathrm{mol}$ higher in energy than the type of isomerization process depicted in eq 3 involving exchange of trans diaxial $\mathrm{CO}$ molecules between adjacent Os atoms. The $5.4 \mathrm{kcal} / \mathrm{mol}$ lower energy of activation that is computed for the isomerization mechanism in eq 3 is consistent with the VT NMR data reported for $\mathrm{CO}$ exchange in $\mathrm{Os}_{3}(\mathrm{CO})_{12-x} \mathrm{P}_{x}$ (where $\left.x=1-4\right)$ and related clusters. In these clusters carbonyl scrambling preferentially occurs by exchanges of pairs of $\mathrm{CO}$ molecules between adjacent Os atoms, rather than by localized, $90^{\circ}$, tripodal, ligand rotations at a single Os metal center. ${ }^{62}$ 

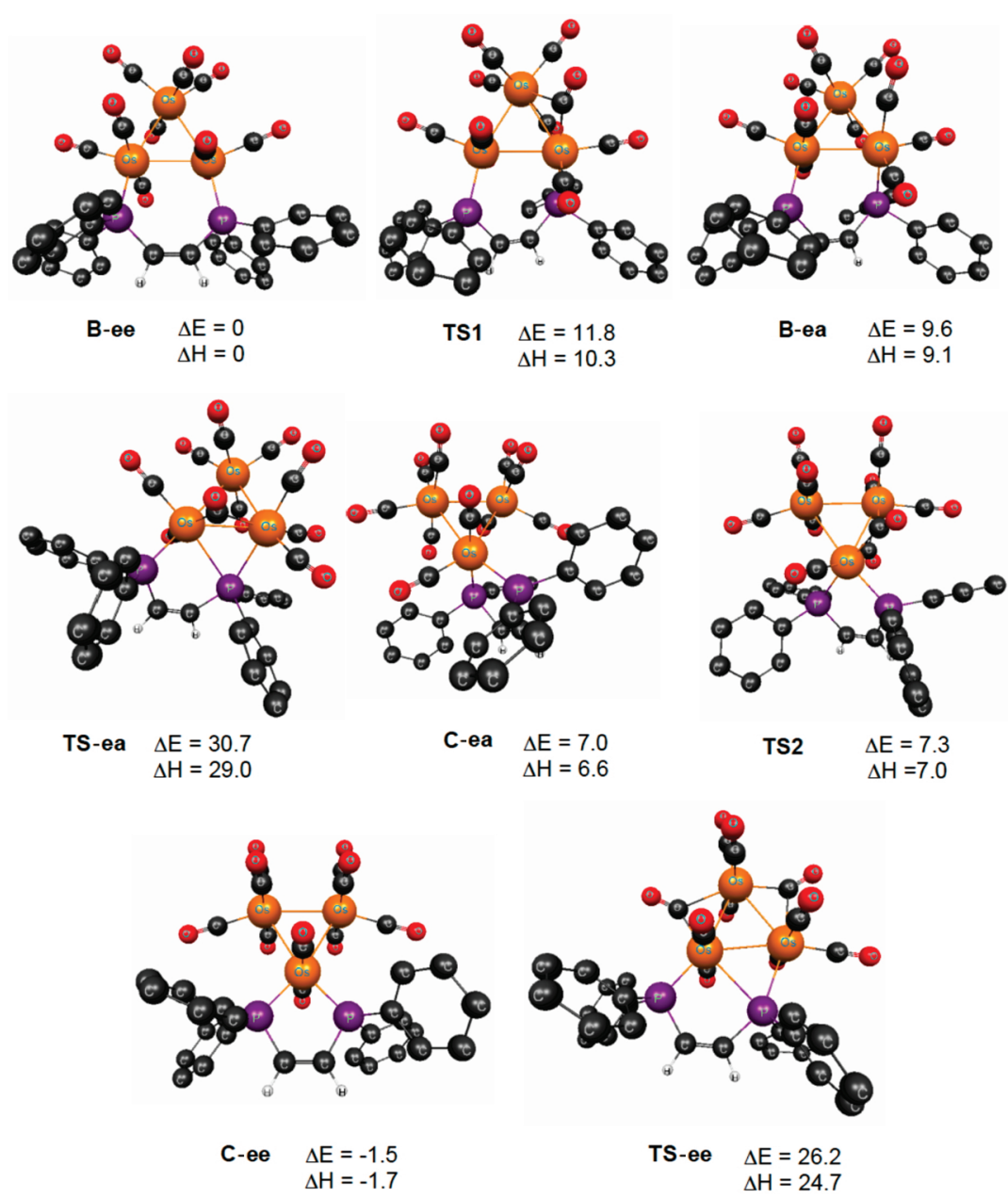

Figure 7. Optimized B3LYP structures for the intermediates and transition structures involved in the two-center and merry-go-round mechanisms for bridged to chelated isomerization reactions of $\mathrm{Os}_{3}(\mathrm{CO})_{10}(\mathrm{dppen}) . \Delta E$ and $\Delta H$ are given in $\mathrm{kcal} / \mathrm{mol}$, relative to B-ee.

approximately in the plane containing the two migrating $\mathrm{CO}$ groups and $\mathrm{Os}_{1}$ and $\mathrm{Os}_{3}$. Equation 3 illustrates the ligand movements starting from bridged 1,2-Os ${ }_{3}(\mathrm{CO})_{10}[(Z)-$ $\mathrm{Ph}_{2} \mathrm{PCH}=\mathrm{CHPPh}_{2}$ (B-ee). (The labeling scheme for the three osmium atoms is that employed in the ensuing discussion of the results of our DFT calculations, and the axial CO groups in eq 3 have been color-coded for clarity).

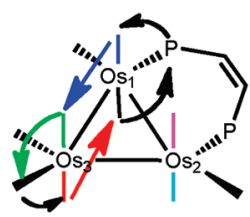

B-ee



$=\mathrm{PPh}$

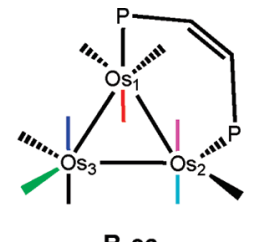

B-ea
After the B-ea isomer has been formed, the axial phosphorus on $\mathrm{Os}_{1}$ can migrate to $\mathrm{Os}_{2}$, concomitant with the migration of the axial $\mathrm{CO}$, trans to the migrating phosphorus, from $\mathrm{Os}_{2}$ to $\mathrm{Os}_{1}$. This process is fundamentally the same as that in eq 3, wherein the double migration again requires conrotation of axial and equatorial $\mathrm{CO}$ groups, but in this case at $\mathrm{Os}_{1}$ and $\mathrm{Os}_{2}$. The migrations, rotations, and

(62) (a) Deeming, A. J.; Donovan-Mtunzi, S.; Kabir, S. E. J. Organomet. Chem. 1985, 281, C43. (b) Alex, R. F.; Pomeroy, R. K. Organometallics 1987, 6, 2437. resulting permutations of the groups attached to these two osmium atoms are shown schematically in eq 4.

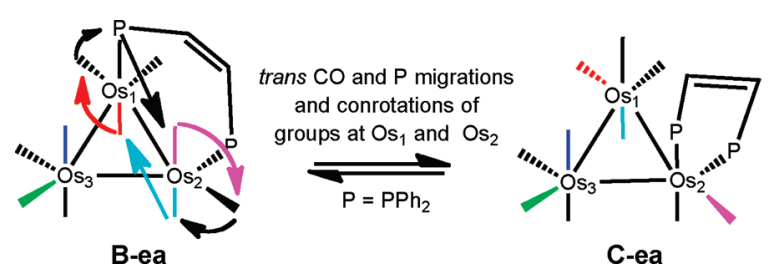

Following the trans $\mathrm{CO}$ and $\mathrm{P}$ migrations in eq 4, the C-ea product is a chelated isomer; however, it has one phosphorus axial and the other equatorial, whereas, 1,1-Os ${ }_{3}(C O)_{10}[(Z)-$ $\mathrm{Ph}_{2} \mathrm{PCH}=\mathrm{CHPPh}_{2}$ ] and all the other chelated diphosphines that have been isolated have both phosphorus atoms equatorial (C-ee). However, as shown in eq 5, a mechanism, similar to those in eqs 3 and 4 and involving migrations between $\mathrm{Os}_{1}$ and $\mathrm{Os}_{2}$ of a pair of trans diaxial $\mathrm{CO}$ groups, would put both of the phosphine groups that are attached to $\mathrm{Os}_{2}$ in equatorial positions.
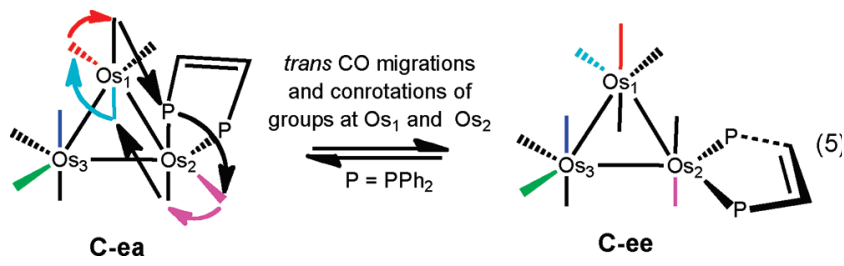


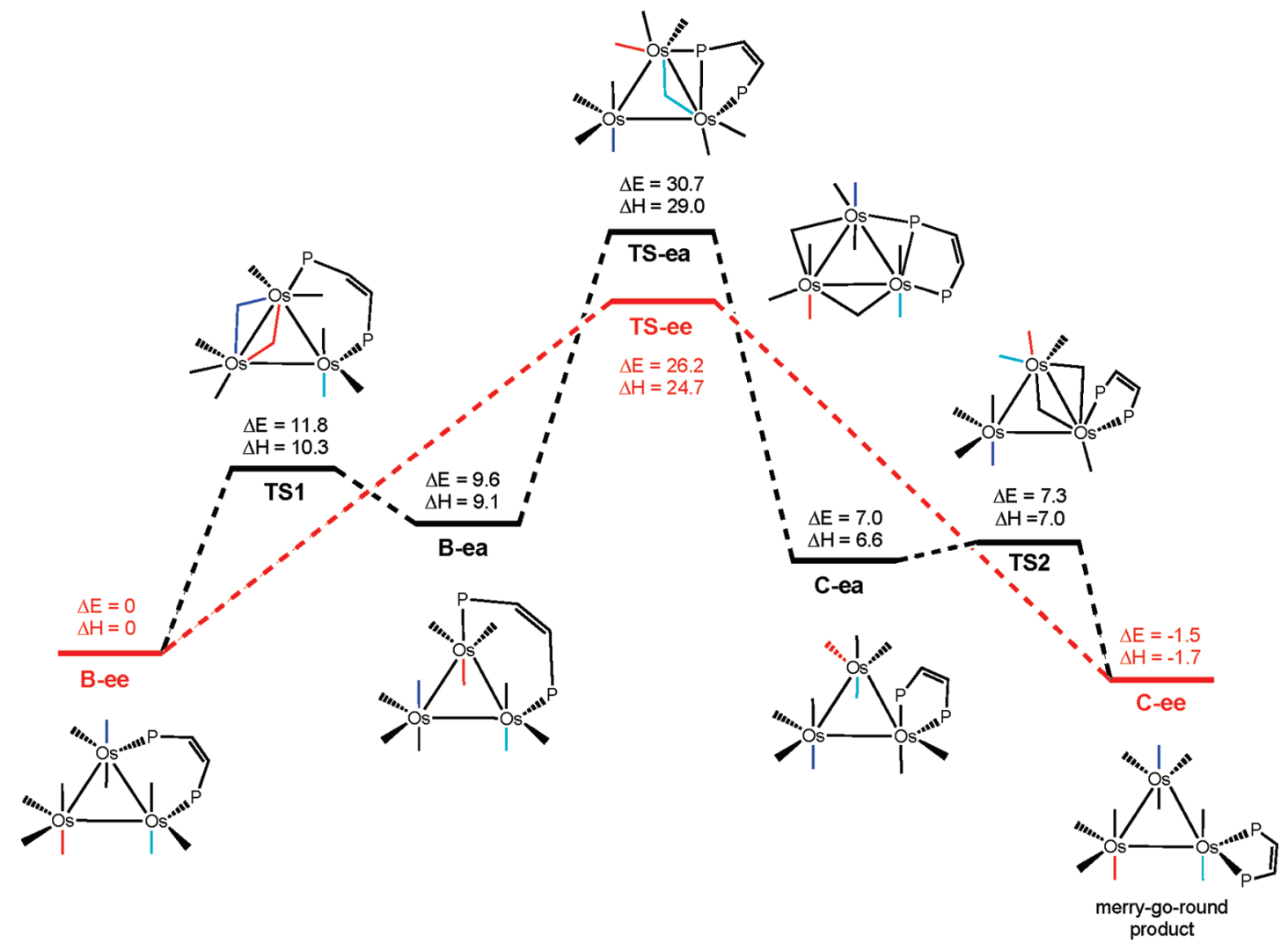

Figure 8. Potential energy surface for the conversion of B-ee to $\mathbf{C}$-ee via in-plane (pairwise) migration and merry-go-round processes (where $\mathrm{P}=\mathrm{PPh}_{2}$ ). $\Delta E$ and $\Delta H$ are given in $\mathrm{kcal} / \mathrm{mol}$, relative to B-ee.

The mechanism that involves a merry-go-round migration of two CO groups and one of the phosphorus atoms in the equatorial plane of the B-ee cluster is shown in eq 6 . This mechanism achieves in one step, involving the simultaneous migration of three equatorial groups, what takes three separate steps in the mechanism that involves the pairwise exchange of a $\mathrm{CO}$ and one of the phosphorus atoms (eq 4). However, the simplicity and economy of the merry-go-round mechanism in eq 6 does not, of course, necessarily make it the energetically preferred mechanism.



VI. Calculations of the Mechanisms and Barrier Heights for Diphosphine Isomerization in $\mathrm{Os}_{\mathbf{3}}(\mathbf{C O})_{10}(\mathbf{P}-\mathbf{P})$. We decided to use the results of electronic structure calculations to determine which of the above mechanisms is favored in the rearrangements of $\mathrm{Os}_{3}(\mathrm{CO})_{10}(\mathrm{P}-\mathrm{P})$ clusters. As a test of our computational prediction of the preferred mechanism, we could assess how well the barrier heights, computed for the preferred mechanism, would reproduce the experimental activation enthalpies in Table 4. If the results of our calculations were thus validated, we could then use them to attempt to understand the observed variations in barrier heights with the structures of the phosphine ligands. For example, we could address the question of why replacement of the etheno group in dppen by the benzo group in dppbz lowers the barrier to rearrangement of $\mathbf{2}$ to $\mathbf{3}$ by $5 \mathrm{kcal} / \mathrm{mol}$ and why fluorination of the benzo group apparently effects an even larger reduction in the enthalpy of activation, as evidenced by our failure to detect $\mathbf{5}$ as an intermediate in the formation of 6.

Our computational studies were initiated by performing DFT calculations on the mechanism of the rearrangements of bridged to chelated $\mathrm{Os}_{3}(\mathrm{CO})_{10}(\mathrm{P}-\mathrm{P})$ clusters, using dppen as the diphosphine ligand. The mechanism involving the pairwise exchange of a $\mathrm{P}$ and a $\mathrm{CO}$ ligand was studied first. Optimized geometries of the two steroisomers of the bridged cluster $1,2-\mathrm{Os}_{3}(\mathrm{CO})_{10}\left[(Z)-\mathrm{Ph}_{2} \mathrm{PCH}=\mathrm{CHPPh}_{2}\right]$ were obtained: one stereoisomer, B-ee, with both phosphorus atoms equatorial, and the other stereoisomer, B-ea, with one phosphorus equatorial and the other axial. B-ea was computed to be higher in enthalpy than B-ee by $9.1 \mathrm{kcal} / \mathrm{mol}$ (the energies and all of the geometrical parameters of the minima and transition structures are given in the Supporting Information)

The mechanism for isomerization of B-ee to B-ea in eq 3 involves the pairwise exchange of the trans diaxial $\mathrm{CO}$ groups across the $\mathrm{Os}_{1}-\mathrm{Os}_{3}$ bond, accompanied by conrotation of four other substituents that are attached to these two osmium atoms. ${ }^{61}$ The transition structure (TS1) is the doubly $\mathrm{CO}$ bridged species shown in Figure 7 . The barrier height for the mechanism in eq 3 was computed to be $10.3 \mathrm{kcal} / \mathrm{mol}$, only $1.2 \mathrm{kcal} / \mathrm{mol}$ higher than the enthalpy of the B-ea isomer.

As shown in eq 4, the bridged intermediate B-ea can be transformed into the chelated structure $\mathbf{C}$-ea by the pairwise exchange of axial $\mathrm{CO}$ and phosphine groups across the $\mathrm{Os}_{2}-\mathrm{Os}_{1}$ bond, concomitant with conrotation of the other 
four groups that lie approximately in the same plane as the two migrating groups and the two osmium atoms to which they are attached. The transition structure (TS-ea) for this process was located, and its structure is given in Figure 7. As shown in Figure 8, TS-ea is calculated to be $29.0 \mathrm{kcal} / \mathrm{mol}$ higher in enthalpy than B-ee and $18.7 \mathrm{kcal} / \mathrm{mol}$ higher than TS1. TS-ea is the highest transition structure in the isomerization of B-ee to C-ee by the three-step mechanism in eqs $3-5$.

TS1 and TS-ea are both doubly bridged. Why is the latter transition structure computed to be so much higher in enthalpy than the former? Part of the reason is that passage from B-ea back to B-ee via TS1 is more exothermic than passage from $\mathbf{B}$-ea to $\mathbf{C}$-ea by $6.6 \mathrm{kcal} / \mathrm{mol}$, but this difference can be only a small contributor to the $18.7 \mathrm{kcal} / \mathrm{mol}$ difference between the two transition structures.

We believe that most of the difference is caused by the fact that in TS1 both of the bridging groups are carbonyls; the presence of an empty $\pi^{*}$ MO in an $\eta^{1}$ terminal CO group makes it easy for the carbonyl to accept a pair of electrons from an adjacent metal atom, to become an $\eta^{2}$ bridging carbonyl group. In contrast, a phosphine does not have such a low-energy, empty MO. This difference between carbonyl groups and phosphines is the reason bridging $\mathrm{CO}$ groups are common in transition-metal chemistry but bridging phosphines are not. It is the bonding of the phosphine group simultaneously to the $\mathrm{Os}_{1}$ and $\mathrm{Os}_{2}$ atoms in TS-ea that makes this transition structure much higher in energy than either TS1 or TS2, in which both of the bridging ligands are CO.

Evidence in support of this explanation for the high energy of TS-ea, relative to TS1 and TS2, comes from bond lengths. For example, the CO that bridges in TS-ea has an average Os $-\mathrm{C}$ bond length that is only $0.204 \AA$ longer in this transition structure than the average length of the Os-C bonds to this carbonyl group in B-ea and C-ea. This is typical of the modest difference between the lengths of the Os-C bonds to the bridging carbonyl groups in TS1, TS2, and TSea and to the terminal carbonyl in B-ee, B-ea, and C-ea. In contrast, the phosphine that bridges in TS-ea has an average Os $-\mathrm{P}$ bond length that is fully $0.355 \AA$ longer in this transition structure than the average length of the Os-P bonds in B-ea and C-ea.

As shown in Figure 8, C-ea is computed to have a $2.5 \mathrm{kcal} /$ mol lower enthalpy than B-ea. A barrier of only $0.4 \mathrm{kcal} / \mathrm{mol}$ is computed to separate $\mathbf{C}$-ea from $\mathbf{C}$-ee by doubly $\mathrm{CO}$ bridged TS2, which is below B-ea by $2.1 \mathrm{kcal} / \mathrm{mol}$. The computed enthalpy difference of $-1.7 \mathrm{kcal} / \mathrm{mol}$ between $\mathbf{B}$-ee and $\mathbf{C}$-ee, in favor of the latter species, compares well with the experimentally determined $\Delta G^{\circ}$ value of $-1.4 \mathrm{kcal} / \mathrm{mol}$ that was obtained in our thermal equilibration studies on $\mathrm{Os}_{3}(\mathrm{CO})_{10}$ (dppen). ${ }^{21 \mathrm{a}}$

There is a plethora of NMR reports on $\mathrm{CO}$ scrambling about triangular faces in polynuclear clusters. ${ }^{63}$ Indeed, our calculations find TS-ee (Figure 8), the triply bridged transition structure for the one-step conversion of B-ee to C-ee in eq 6 , to be $4.3 \mathrm{kcal} / \mathrm{mol}$ lower in enthalpy than TS-ea, the highest energy transition structure for the three-step conversion of B-ee to $\mathbf{C}$-ee via the mechanism in eqs $3-5$. That

(63) (a) Cotton, F. A. Inorg. Chem. 1966, 5, 1083. (b) Orlandi, A.; Frey, U.; Suardi, G.; Merbach, A. E.; Roulet, R. Inorg. Chem. 1992, 31, 1304. (c) Aime, S.; Dastrù, W.; Gobetto, R.; Krause, J.; Violano, L. Inorg. Chim. Acta 1995, 235, 357. (d) Besancon, K.; Laurenczy, G.; Lumini, T.; Roulet, R.; Bruyndonckx, R.; Daul, C. Inorg. Chem. 1998, 37, 5634. (e) Waterman, S. M.; Humphrey, M. G. Organometallics 1999 , 18, 3116. (f) Canal, J. P.; Jennings, M.; Yap, G. P. A.; Pomeroy, R. K. Dalton Trans. 2008, 1375.
TS-ee is, indeed, a bona fide transition structure and not a short-lived intermediate on the PES for rearrangement of Bee to $\mathbf{C}$-ee was verified by normal-mode analysis, which found an imaginary frequency of $77 i$ for TS-ee. An IRC calculation confirmed that TS-ee does, in fact, connect B-ee directly to C-ee.

It should be noted, however, that in $\mathrm{Os}_{3}(\mathrm{CO})_{12}$, a $D_{3 h}$ structure with three bridging equatorial carbonyls is calculated to be ca. $5 \mathrm{kcal} / \mathrm{mol}$ higher in energy than a $C_{2 v}$ doubly bridged transition structure for exchanging a pair of trans diaxial carbonyl groups. ${ }^{64}$ Therefore, at first it seems surprising that the preferred mechanism for the rearrangement of $\mathbf{B}-$ ee to $\mathbf{C}$-ee is predicted to occur via the triply bridged, merrygo-round transition structure (TS-ee), rather than by the doubly bridged transition structure for exchange of an axial phosphine and a trans axial $\mathrm{CO}$ between just two Os atoms (TS-ea). Nevertheless, the results of the calculations by Li et al. on $\mathrm{Os}_{3}(\mathrm{CO})_{12}{ }^{64}$ and ours on $\mathrm{Os}_{3}(\mathrm{CO})_{10}[(\mathrm{Z})$ $\mathrm{Ph}_{2} \mathrm{PCH}=\mathrm{CHPPh}_{2}$ ] are, in fact, wholly consistent with each other. As shown in Figure 8, although TS-ee is $4.3 \mathrm{kcal} / \mathrm{mol}$ lower in enthalpy than TS-ea, $9.1 \mathrm{kcal} / \mathrm{mol}$ of the enthalpy of TS-ea comes from the enthalpy that is required to isomerize B-ee to B-ea, so that the ligand exchange reaction can occur. Starting from B-ea, the barrier to exchange of an axial phosphine and a trans axial CO via TS-ea is only $\Delta H^{\ddagger}=$ $19.9 \mathrm{kcal} / \mathrm{mol}$, which is $4.8 \mathrm{kcal} / \mathrm{mol}$ lower than $\Delta H^{\ddagger}=24.7$ $\mathrm{kcal} / \mathrm{mol}$ for exchange of three equatorial ligands via TS-ee.

Unfortunately, the B3LYP/SDD calculations on $\mathrm{Os}_{3}$ $(\mathrm{CO})_{12}$ by $\mathrm{Li}$ et al. were performed without polarization functions in the D95 basis set. ${ }^{64}$ Therefore, the barrier heights to rearrangement, computed by $\mathrm{Li}$ et al., are not directly comparable to the barrier heights for rearrangement of $\mathrm{Os}_{3}(\mathrm{CO})_{10}\left[(Z)-\mathrm{Ph}_{2} \mathrm{PCH}=\mathrm{CHPPh}_{2}\right]$, computed by us with the $\mathrm{D} 95^{*}$ basis set on phosphorus, oxygen, and carbon. In order to make meaningful comparisons between the barrier heights for rearrangement of these two molecules, we repeated the B3LYP/SDD calculations on $\mathrm{Os}_{3}(\mathrm{CO})_{12}$ with the D95* basis set on phosphorus, oxygen, and carbon.

Our calculations on $\mathrm{Os}_{3}(\mathrm{CO})_{12}$ found the energies of the doubly bridged $C_{2 v}$ and triply bridged $D_{3 h}$ transition structures to be respectively 13.0 and $17.7 \mathrm{kcal} / \mathrm{mol}$ higher than that of the $D_{3}$ equilibrium geometry. Both of these transition structure energies are $4.7 \mathrm{kcal} / \mathrm{mol}$ higher than the values published by $\mathrm{Li}$ et al. Clearly, inclusion of polarization functions in the basis sets for carbon and oxygen stabilizes the equilibrium geometry of $\mathrm{Os}_{3}(\mathrm{CO})_{12}$ more than the transition structures for $\mathrm{CO}$ migrations in this molecule.

The energy $\Delta \mathrm{E}=13.0 \mathrm{kcal} / \mathrm{mol}$ for the doubly bridged $\mathrm{Os}_{3}(\mathrm{CO})_{12}$ transition structure, relative to the equilibrium geometry, is $8.1 \mathrm{kcal} / \mathrm{mol}$ smaller than $\Delta E=21.1 \mathrm{kcal} / \mathrm{mol}$ between TS-ea and B-ea; the relative energy $\Delta \mathrm{E}=17.7 \mathrm{kcal} /$ mol for the triply bridged $\mathrm{Os}_{3}(\mathrm{CO})_{12}$ transition structure is $8.5 \mathrm{kcal} / \mathrm{mol}$ smaller than $\Delta E=26.2 \mathrm{kcal} / \mathrm{mol}$ between TSee and B-ee. Therefore, we believe that ca. $8 \mathrm{kcal} / \mathrm{mol}$ represents a reasonable estimate of the energetic penalty paid by $\mathrm{Os}_{3}(\mathrm{CO})_{10}\left[(Z)-\mathrm{Ph}_{2} \mathrm{PCH}=\mathrm{CHPPh}_{2}\right]$, relative to $\mathrm{Os}_{3}$ $(\mathrm{CO})_{12}$, for having a bridging phosphine in place of a bridging carbonyl group in the transition structures for ligand exchanges between both two and three Os atoms. ${ }^{65}$

The calculated activation parameters of $\Delta H^{\ddagger}=24.7 \mathrm{kcal} /$ mol and $\Delta S^{\ddagger}=-2.7 \mathrm{cal} /(\mathrm{mol} \mathrm{K})$ for isomerization of $\mathbf{B}$-ee to

(64) Li, Q.-S.; Xu, B.; Xie, Y.; King, R. B.; Schaefer, H. F. Dalton Trans. 2007, 4312 . 
Table 5. Computed Energy and Enthalpy Differences between the Bridged and Chelated $\mathrm{Os}_{3}(\mathrm{CO})_{10}($ diphosphine) Isomers and Computed Activation Energies and Enthalpies for the Bridged to Chelated Isomerization Reaction via the Merry-Go-Round Mechanism ${ }^{d}$

Diphosphine Ligands
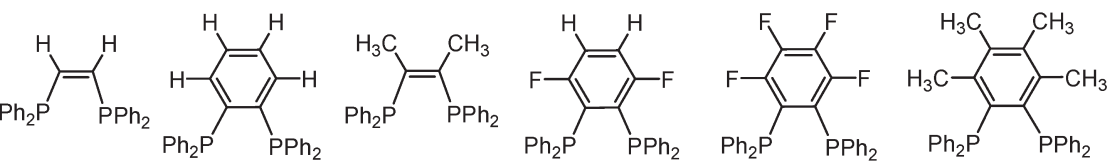

\begin{tabular}{crrcccc} 
& a & b & c & d & e & f \\
\hline$\Delta \mathrm{E}$ & -1.5 & -6.7 & -8.2 & -10.7 & -11.2 & -21.6 \\
$\Delta \mathrm{H}$ & -1.7 & -6.7 & -8.2 & -11.1 & -10.8 & -21.5 \\
$\Delta \mathrm{E}^{\ddagger}$ & 26.2 & 23.8 & 24.7 & 20.2 & 19.3 & $\mathrm{a}$ \\
$\Delta \mathrm{H}^{\neq}$ & $24.7^{\mathrm{b}}$ & $22.5^{\mathrm{c}}$ & 23.6 & 18.9 & 18.2 & $\mathrm{a}$
\end{tabular}

\footnotetext{
${ }^{a}$ Due to the size of and numbers of degrees of freedom in this ligand, no attempt was made to locate the transition structure for the rearrangement of the bridged to the chelated isomer. ${ }^{b}$ The corresponding experimental value for entry a is $\Delta H^{\ddagger}=26.5(6) \mathrm{kcal} / \mathrm{mol}$. ${ }^{c}$ The corresponding experimental value for entry b is $\Delta H^{\ddagger}=21.6(3) \mathrm{kcal} / \mathrm{mol} .{ }^{d}$ All energies are in $\mathrm{kcal} / \mathrm{mol}$.
}

C-ee via triply bridged TS-ee are in good agreement with the experimental values (Table 4) of $\Delta H^{\ddagger}=26.5(6)$ and $\Delta S^{\ddagger}=-5(2) \mathrm{cal} /(\mathrm{mol} \mathrm{K}) .^{21 \mathrm{a}}$ This agreement provides support for the computational finding that the one-step, merrygo-round mechanism in eq 6 really is preferred to the threestep mechanism in eqs $3-5$ for the rearrangement of $\mathbf{B}$-ee to C-ee. As discussed in section VII, further evidence comes from the good agreement of the activation parameters, calculated for the rearrangements via merry-go-round transition structures of $\mathrm{Os}_{3}(\mathrm{CO})_{10}(\mathrm{P}-\mathrm{P})$ complexes, containing other diphosphine ligands (Table 5), with the values obtained experimentally (Table 4).

VII. Computed Reactivity Trends as a Function of the Ancillary Diphosphine Ligand in Isomeric $\mathrm{Os}_{\mathbf{3}}(\mathrm{CO})_{10}(\mathrm{P}-\mathrm{P})$ Clusters. Having established computationally that the merry-go-round scenario is the operative mechanism for the isomerization, from bridging to chelating, of the diphosphine ligand in 1,2- and $1,1-\mathrm{Os}_{3}(\mathrm{CO})_{10}\left[(Z)-\mathrm{Ph}_{2} \mathrm{PCH}=\right.$ $\mathrm{CHPPh}_{2}$, we computed the energetics associated with this mechanism for the isomerization of other rigid diphosphine ligands about the triosmium cluster. The results of these calculations are summarized in Table 5. All of the isomerization reactions are computed to be exothermic. The calculated $\Delta H$ values for the isomerizations display more than an order of magnitude difference, ranging from $\Delta H=-1.7 \mathrm{kcal} / \mathrm{mol}$ for the dppen ligand (entry a) to $\Delta H=-21.5 \mathrm{kcal} / \mathrm{mol}$ for the highly substituted 1,2-bis(diphenylphosphino)-2,3,4,5tetramethylbenzene ligand (entry f).

The calculated activation enthalpies range from $\Delta H^{\ddagger}=$ $24.7 \mathrm{kcal} / \mathrm{mol}$ for the dppen ligand to $\Delta H^{\ddagger}=18.2 \mathrm{kcal} / \mathrm{mol}$ for the dppbzF 4 ligand (entry e), the most highly substituted diphosphine that has been studied experimentally. The computed value of $\Delta H^{\ddagger}=22.5 \mathrm{kcal} / \mathrm{mol}$ for the isomerization of $\mathbf{2}$ to $\mathbf{3}$ (entry $\mathbf{b}$ in Table 5) agrees well with the value of $\Delta H^{\ddagger}=$ $21.6(3) \mathrm{kcal} / \mathrm{mol}$, measured in the current study (Table 4). Upon perfluorination of the benzo group, the enthalpy of activation for rearrangement is computed to decrease by 4.3 $\mathrm{kcal} / \mathrm{mol}$ for the isomerization of $\mathbf{5}$ to $\mathbf{6}$ (entry e in Table 5).

(65) We find that a similar energetic penalty of ca. $8 \mathrm{kcal} / \mathrm{mol}$ is incurred when the $\mathrm{PH}_{3}$ group in $\mathrm{Os}_{3}(\mathrm{CO})_{11}\left(\mathrm{PH}_{3}\right)$ replaces a bridging $\mathrm{CO}$ in $\mathrm{Os}_{3}(\mathrm{CO})_{12}$ in the two-center and three-center transition structures for rearrangement.

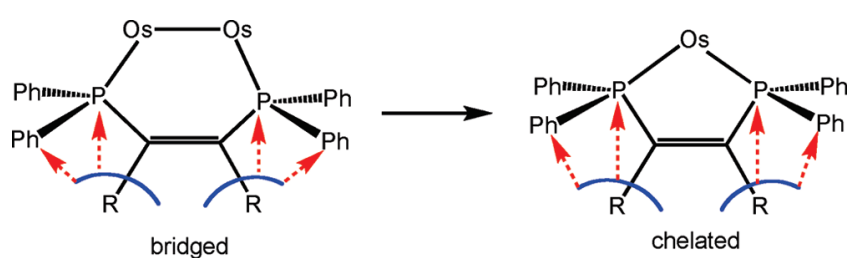

Figure 9. Schematic depiction of how, on going from the bridged to the chelated isomer, the decrease in $\mathrm{P}-\mathrm{C}-\mathrm{C}$ bond angle and the concomitant increase in the $\mathrm{R}-\mathrm{C}-\mathrm{P}$ angle reduce the steric interactions between each phosphorus atom and the phenyl groups attached to it with the $\mathrm{R}$ group that is bonded to the same carbon atom as the phosphorus.

The size of this decrease is consistent with our conjecture that the reason only chelated isomer 6 was observed in the reaction between $\mathbf{1}$ and $\mathrm{dppbzF}_{4}$ is that $\mathbf{5}$ rearranges to $\mathbf{6}$ too quickly to be detected in our experiments.

The computational results in Table 5 underscore the influence that steric effects within the diphosphine ligands have on both the thermodynamics and kinetics of these isomerization reactions. As already discussed in section $\mathrm{I}$, in connection with the X-ray structures of $\mathbf{2}$ and $\mathbf{3}$, the rearrangement of the former to the latter decreases the $\mathrm{C}-\mathrm{C}-\mathrm{P}$ bond angle from ca. $126^{\circ}$ in the six-membered ring of 2 to ca. $117^{\circ}$ in the fivemembered ring of $\mathbf{3}$. Similar sized reductions in these internal angles are calculated to occur in the rearrangements of the bridged to the chelated isomers for all of the ligands in Table 5 (see the Supporting Information for the optimized structures). As shown schematically in Figure 9, decreasing the $\mathrm{C}-\mathrm{C}-\mathrm{P}$ bond angle and, concomitantly, increasing the $\mathrm{R}-\mathrm{C}-\mathrm{P}$ angle reduce the strain that is engendered by steric interactions between each phosphorus atom and the phenyl groups attached to it with the group, $\mathrm{R}$, that is bonded to the same carbon as the phosphorus. Consequently, as the size of the R group increases, so does the amount of strain relieved by the rearrangement of the bridged to the chelated isomer, and as might be anticipated, the increased exothermicity of this reaction lowers the height of the barrier to it.

The effective size of the $\mathrm{R}$ group increases from left to right across Table 5 , from $\mathrm{R}=\mathrm{H}$ in entry a to $\mathrm{R}=\mathrm{C}-\mathrm{CH}_{3}$ for the $o$-methyl groups in entry $\mathbf{f}$, and the exothermicity of the conversion of the bridged to the chelated isomer also 
increases in magnitude across Table 5. An exception to this trend is provided by entries $\mathbf{d}$ and $\mathbf{e}$, where the two additional fluorines in the meta positions of entry e have little effect on the exothermicity of the rearrangement. This fact provides evidence that the exothermicity of the rearrangements of both of these fluorinated ligands is due to steric effects from the $o$-fluorines, rather than to electronic factors.

To the extent that the steric interactions between the geminal $\mathrm{R}$ and $\mathrm{PPh}_{2}$ groups in the bridged isomer decrease, not only in the chelated isomer but also in the transition structure leading to it, one might expect the barrier heights to decrease with the size of $\mathrm{R}$ and, hence, with the increase in the magnitude of the exothermicity of the rearrangement. ${ }^{66}$ An exception to the correlation between increased exothermicity and decreased barrier height is $\mathrm{R}=\mathrm{CH}_{3}$ (entry c). Although the exothermicity of the rearrangement of entry $\mathbf{c}$ is computed to be $1.5 \mathrm{kcal} / \mathrm{mol}$ greater than that of entry $\mathbf{b}(\mathrm{R}=$ $\mathrm{C}-\mathrm{H}$ ), the barrier to the rearrangement of entry $\mathbf{c}$ is actually computed to be $1.1 \mathrm{kcal} / \mathrm{mol}$ higher than that of entry $\mathbf{b}$. Apparently the methyl groups in entry c undergo some small destabilizing interactions in the transition structure for rearrangement that are absent in the chelated product.

If the increase in exothermicity and decrease in barrier height in Table 5 both have their origin in relief of strain in the bridged reactant, the effect of the size of $\mathrm{R}$ should have a larger influence on the exothermicity than on the barrier height. For example, the $9.1 \mathrm{kcal} / \mathrm{mol}$ calculated increase in exothermicity from entry a to entry $\mathbf{e}$ is accompanied by only a $6.9 \mathrm{kcal} / \mathrm{mol}$ decrease in barrier height. As would be expected, relief of the strain that is present in the bridged reactant is less complete in the transition structure leading to the chelated product than in the chelated product itself.

(66) A reviewer has suggested that charge effects, as opposed to steric effects, may be important in the transition state of our isomerization reactions, especially for the $\mathrm{dppz}$ and $\mathrm{dppzF}_{4}$ ligands. With the $o-\left(\mathrm{Ph}_{2} \mathrm{P}\right)_{2} \mathrm{C}_{6} \mathrm{~F}_{4}$ ligand, the migrating phosphine $\left(\mathrm{P}_{1}\right)$ shows evidence for enhanced rehybridization in the TS, in order to help relieve the steric interaction between the $\mathrm{P}_{1} \mathrm{Ph}_{2}$ group and the adjacent fluorine (the $\mathrm{Ph}-\mathrm{P}_{1}-\mathrm{Ph}$ angle is $113.8^{\circ}$ in the dppbzF $\mathrm{TS}_{4}$ vs $108.6^{\circ}$ in the dppbz TS, as illustrated below). This angular change leads to a flattening of $P_{1}$, and this allows it to bond to $\mathrm{Os}_{2}$ more strongly in the dppbzF $\mathrm{F}_{4} \mathrm{TS}$ than in the dppbz TS, as shown by $\mathrm{Os}_{2}-\mathrm{P}_{1}$ bond lengths of $2.75 \AA$ and $3.05 \AA$, respectively (see the Supporting Information). The additional electron donation from the $\mathrm{P}_{1} \mathrm{Ph}_{2}$ group in the dppbzF $\mathrm{F}_{4}$ TS makes $\mathrm{Os}_{2}$ more negative than in the dppbz TS $(-1.546$ vs -1.487$)$. Although $\mathrm{P}_{1}$ is slightly more positive in the former TS than in the latter (1.119 vs 1.100 ), most of the positive charge that one might have expected to find on $\mathrm{P}_{1}$ seems to be neutralized by the transfer of electrons from $\mathrm{Os}_{1}$ back to $\mathrm{P}_{1}$. The charges on $\mathrm{Os}_{1}$ are respectively -1.324 and -1.403 in the dppbzF TS and dppbz TS. Since the NBO charges for the bridged and chelated isomers of the dppz- and $\mathrm{dppzF}_{4}$-substituted clusters reveal no significant differences, NBO differences in the TS charges are best viewed as arising from the rehybridization that accompanies the $\mathrm{P}_{1}$ atom in the $\mathrm{dppzF}_{4} \mathrm{TS}$, relative to the dppz TS, as influenced by the neighboring fluorine atom.
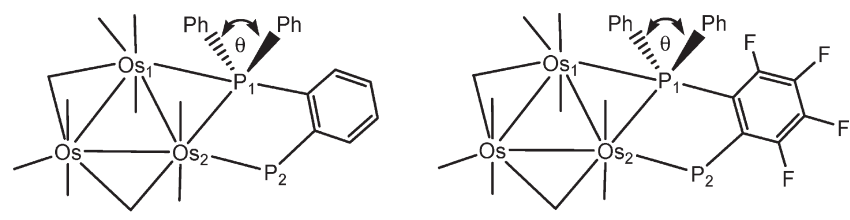

$$
\begin{gathered}
\theta=108.6^{\circ} \\
O s_{1}=-1.403 \\
O s_{2}=-1.487 \\
P_{1}=1.100 \\
P_{2}=1.230
\end{gathered}
$$

\section{Conclusions}

The synthesis and characterization of new dppbz- and dppbzF $4^{-}$ substituted triosmium decacarbonyl clusters are reported, and the rate of conversion of bridged $1,2-\mathrm{Os}_{3}(\mathrm{CO})_{10}(\mathrm{dppbz})(2)$ to chelated $1,1-\mathrm{Os}_{3}(\mathrm{CO})_{10}(\mathrm{dppbz})(3)$ has been measured over a $25^{\circ} \mathrm{C}$ temperature range. The slightly negative entropy of activation supports a nondissociative mechanism for the isomerization process.

The results of DFT calculations indicate that a merry-goround mechanism, involving the concerted exchange of $\mathrm{CO}$ and diphosphine ligands about the equator of the cluster polyhedron is the lowest energy pathway. The calculations confirm the ability of a tertiary phosphine to function in a nonclassical coordination mode and to simultaneously bind to adjacent metal centers in a bridging fashion. However, calculations of the barrier heights for pairwise exchange of axial ligands indicate the bridging by phosphorus provides considerably less stabilization than bridging by a carbonyl carbon. Comparison of the energies computed for P-bridged structures in $\mathrm{Os}_{3}(\mathrm{CO})_{10}[(Z)$ $\mathrm{Ph}_{2} \mathrm{PCH}=\mathrm{CHPPh}_{2}$ ] and the corresponding doubly and triply $\mathrm{CO}$ bridged structures in $\mathrm{Os}(\mathrm{CO})_{12}$ indicates an energy penalty of about $8 \mathrm{kcal} / \mathrm{mol}$ for $\mathrm{P}$ versus $\mathrm{CO}$ bridging.

Increasing the effective size of the substituent, $\mathrm{R}$, that is attached to the same carbon as phosphorus in the diphosphine ligands is shown, by the results of both our experiments and our calculations, to increase the reactivity of the bridging diphosphine ligand in this genre of cluster compounds. DFT calculations also find that increasing the geminal substituent size has an even greater effect on increasing the exothermicity of the rearrangement of the bridged to the chelated isomer. These findings are attributed to the ca. $10^{\circ}$ decrease in the $\mathrm{C}-\mathrm{C}-\mathrm{P}$ bond angle that occurs during the transformation of the sixmembered ring in the bridged isomer to the five-membered in the chelated isomer and the concomitant increase in the $\mathrm{R}-\mathrm{C}-\mathrm{P}$ angle. Increasing the latter angle decreases the magnitude of the nonbonded interactions of phosphorus and the phenyl groups attached to it with the substituent that is attached to the same carbon. The larger the effective size of the substituent group, R, the larger is the amount of steric strain removed on the rearrangement of the bridged to the chelated isomer of $\mathrm{Os}_{3}(\mathrm{CO})_{10}(\mathrm{P}-\mathrm{P})$.

Acknowledgment. Financial support from the Robert A. Welch Foundation (Grant B-0027 to W.T.B. and Grant B-1093 to M.G.R.) and from the National Science Foundation (to W.T.B.) is greatly appreciated. X.W. acknowledges support by the U.S. Department of Energy, Office of Science, under Contract No. DE-AC05-00OR22725 managed by UT Battelle, LLC. The NSF-MRI program grant CHE-0840518 is gratefully acknowledged for support of the NMR facilities at UNT. NSF support of the UNT computational facilities through grant CHE-0741936 is acknowledged. Preliminary experimental work conducted by $\mathrm{Mr}$. Sean Hunt and preliminary calculations by Dr. Haiyan Wei are acknowledged.

Supporting Information Available: Text, figures, tables, and CIF files giving an Eyring plot of the dppbz isomerization data, atomic coordinates and energies of all optimized stationary points and transition states, NBO charges and selected bond distances for the merry-go-round TS structures containing dppz and $\mathrm{dppzF}_{4}$ ligands, and crystallographic data. This material is available free of charge via the Internet at http://pubs.acs.org. 